\title{
Climate of the upper atmosphere
}

\author{
Jürgen Bremer $\left({ }^{1}\right)$, Jan Laštovička $\left({ }^{2}\right)$, Andrei V. Mikhailov $\left({ }^{3}\right)$, David Altadill $\left({ }^{4}\right)$, Pal Bencze $\left({ }^{5}\right)$, \\ Dalia Burešová $\left({ }^{2}\right)$, Giorgiana De Franceschi $\left({ }^{6}\right)$, Christoph Jacobi $\left({ }^{7}\right)$, Stamatis Kouris $\left({ }^{8}\right)$, \\ Loredana Perrone $\left({ }^{6}\right)$ and Esa Turunen $\left({ }^{9}\right)$ \\ (') Leibniz-Institute of Atmospheric Physics, Kühlungsborn, Germany \\ $\left.{ }^{(}\right)$Institute of Atmospheric Physics, Academy of Sciences of Czech Republic, Prague, Czech Republic \\ $\left(^{3}\right)$ Institute of Terrestrial Magnetism, Ionosphere and Radio Wave Propagation (IZMIRAN), \\ Russian Academy of Sciences, Troitsk (Moscow Region), Russia \\ $\left({ }^{4}\right)$ Observatori de l'Ebre, Universitat Ramon Llull - CSIC, Spain \\ ${ }^{5}$ ) Geodetic and Geophysical Research Institute, Hungarian Academy of Sciences, Sopron, Hungary \\ $\left({ }^{6}\right)$ Istituto Nazionale di Geofisica e Vulcanologia, Roma, Italy \\ ${ }^{(7)}$ Institute for Meteorology, University of Leipzig, Leipzig, Germany \\ $\left(^{8}\right)$ Electrical and Computer Engineering Department, Aristotle University of Thessaloniki, Greece
}

${ }^{9}$ ) Sodankylä Geophysical Observatory, Sodankylä, Finland

\begin{abstract}
In the frame of the European COST 296 project (Mitigation of Ionospheric Effects on Radio Systems, MIERS) investigations of the climate of the upper atmosphere have been carried out during the last four years to obtain new information on the upper atmosphere. Mainly its ionospheric part has been analysed as the ionosphere is most essential for the propagation of radio waves. Due to collaboration between different European partners many new results have been derived in the fields of long-term trends of different ionospheric and related atmospheric parameters, the investigations of different types of atmospheric waves and their impact on the ionosphere, the variability of the ionosphere, and the investigation of some space weather effects on the ionosphere.
\end{abstract}

Key words Ionosphere - trends - atmospheric waves - ionospheric variability - incoherent radar - space weather

\section{Introduction}

The propagation of radio waves through the ionosphere is strongly influenced by its regular variations (diurnal, seasonal, solar cycle) as well as different short- and long-term changes. Whereas the influence of the regular ionospheric variations on the radio wave propagation is

Mailing address: Dr. Jürgen Bremer, Leibniz-Institute of Atmospheric Physics, Schloss-Str. 6 D-18225 Kühlungsborn, Germany; e.mail: bremer@iap-kborn.de more or less well known from many investigations during the last century, the influence of more irregular ionospheric variations of different time scales needs further studies. Investigations of these effects should contribute to a better understanding of these phenomena and may help to develop new systems to mitigate their influences.

To be able to mitigate ionospheric effects on radio systems successfully, we first must know what to mitigate, what are ionospheric threats, and to know it, we need to know and understand the background state of the ionosphere (ionospheric climatology) and its disturbances and changes, which is the goal of the paper. The paper includes new results of the investigation of long-term trends in different ionospheric and atmospheric parameters. Two essential points are the practical importance of such trends and 
their origin. Another important topic deals with the detection of different atmospheric waves (here restricted to planetary, gravity, and infrasonic waves) and their influence on the ionosphere. In the field of ionospheric variability different ionospheric parameters are analysed for their diurnal, seasonal, and solar cycle dependence as well as in dependence on height. In this context the detection and analysis of ionospheric disturbances which are not caused by geomagnetic activity is a new interesting point ( $Q$-disturbances). For a better understanding of different ionospheric phenomena observations with large incoherent radars as well as model calculations are important as demonstrated by the interpretation of the $Q$-disturbances and effects of precipitating high energetic particle fluxes into the atmosphere. Finally some results are presented concerning different space weather effects onto the ionosphere.

\section{Long-term trends in different ionospheric and related atmospheric parameters and their origin}

Roble and Dickinson (1989) presented the first theoretical simulations of the effects of increasing greenhouse gas concentrations on the upper atmosphere and ionosphere. These studies predicted substantial temperature reductions in the upper atmosphere with doubled $\mathrm{CO}_{2}$, i.e. greenhouse cooling. The global atmosphere is very nearly in a hydrostatic equilibrium, which means that the height of a given pressure surface is determined by the average atmospheric temperature below. The cooling is therefore expected to result in thermal contraction of the upper atmosphere and we may expect a significant decline in thermospheric density at fixed heights as well as a downward displacement of ionospheric layers (Rishbeth, 1990; Rishbeth and Roble, 1992).

A first scenario of global change in the upper atmosphere at heights above $50 \mathrm{~km}$, i.e. in the mesosphere, thermosphere and ionosphere, was constructed with principal participation of COST 296 scientists. It is shown in fig. 1 and described in detail by Laštovička et al. (2006a, 2008a). Its main feature is cooling of the upper atmosphere (except for the mesopause region with probably no significant temperature trend), which should result in thermal contraction of the mesosphere and thermosphere. This thermal contraction has been confirmed for the thermosphere by analysing density data series obtained from satellite drag (Emmert et al., 2004). The reduction of thermospheric density at fixed heights has a positive impact on orbital lifetime of satellites. In the ionosphere, a decrease of the lowermost ionosphere and the maximum height of the $E$-region $(h m E)$ is observed together with some increase of electron concentration at fixed heights in the lowermost ionosphere and slight increase of maximum electron concentrations of the $E$ - and $F 1$-layers, represented by critical frequencies $f o E$ and foF 1 . As for the $F 2$ region, the results of various authors have been controversial both in the sign/sense of changes and their origin.

The known potential drivers of upper atmospheric long-term global change include first of all increasing concentrations of greenhouse gases $\left(\mathrm{CO}_{2}, \mathrm{CH}_{4}\right.$ and others), then anthropogenic changes of the ozone layer, natural long-term variations of geomagnetic activity, all increased throughout the 20th Century, and long-term changes of the Earth's magnetic field (unimportant in Europe). The observed positive electron density trends in the lower ionosphere are qualitatively consistent with thermal contraction of the mesosphere. Trends in the ionospheric $E$ and $F 1$-region parameters, in ion temperature near $350 \mathrm{~km}$ and average $F$-region temperature, and in thermospheric densities between 200 and $800 \mathrm{~km}$, are also qualitatively consistent with the expected effect of greenhouse cooling and contraction of the upper atmosphere; the greenhouse cooling changes chemistry of minor constituents, which is the main driver of the observed changes in $f o E$ and $f o F 1$.

Three main areas of gaps or discrepancies were established by Laštovička et al. (2008a). Their key words are: 1) F2-region ionosphere, 2) MLT (mesosphere/lower thermosphere) dynamics, 3) MLT water vapour. Item 1) includes contradiction among various results on trends in foF 2 and $h m F 2$ and their drivers. Item 2) consists of unstable and/or non-linear trends in MLT winds and largely unknown and/or uncer- 


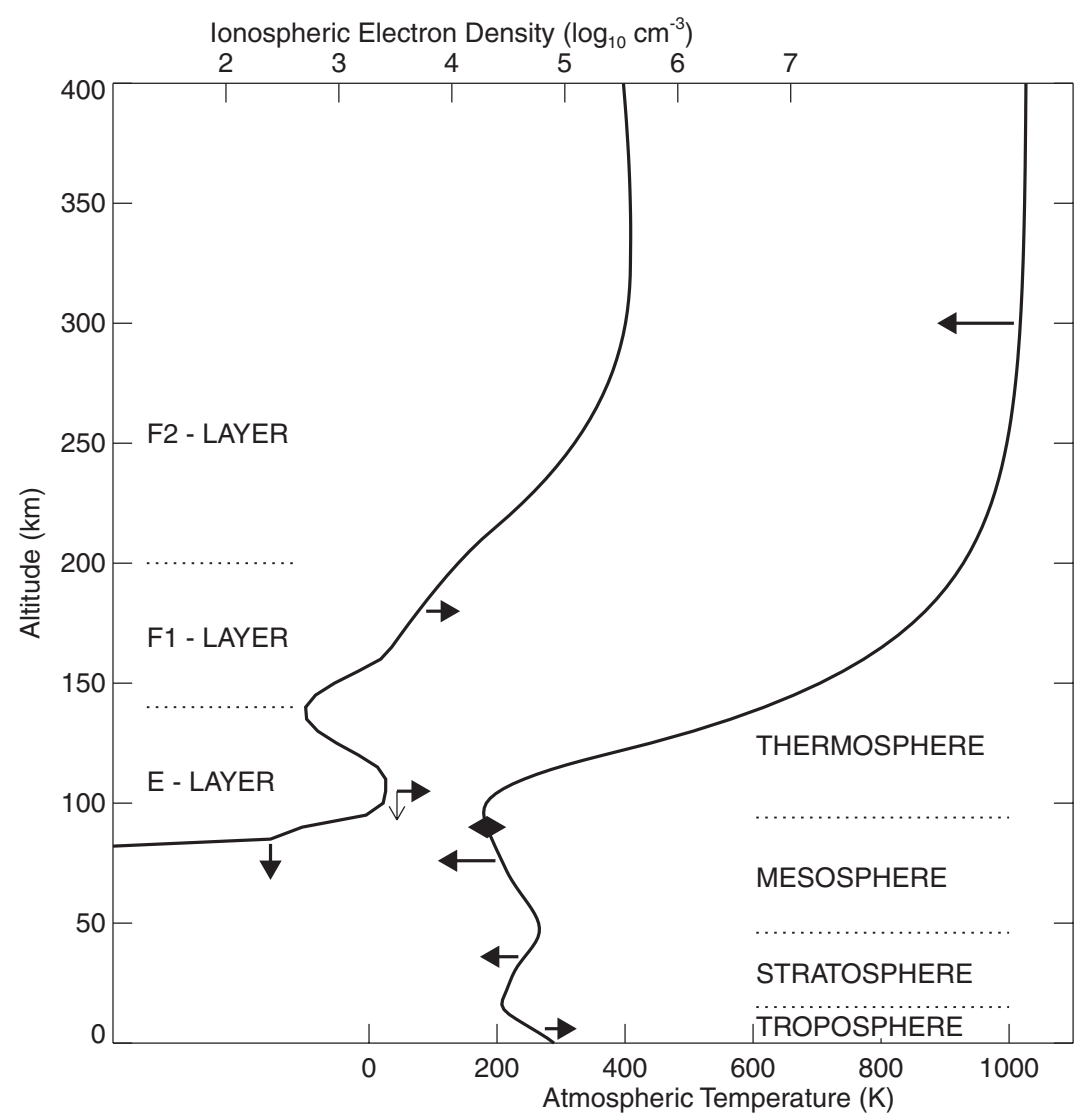

Fig. 1. Trends in the ionosphere and atmosphere. The ionospheric layers are defined by the electron density profile (midnight). The atmospheric layers are defined by the temperature profile. Arrows indicate the direction of long-term changes (Laštovička et al., 2008a).

tain trends in atmospheric wave activity in MLT. For ionospheric physics and radio propagation, item 1) is of primary interest due to principal importance of $f o F 2$ for radio propagation. Item 2 ) is also important, because atmospheric waves filtered by winds are the primary factor of coupling to the ionosphere from below.

In literature there are large discrepancies and controversies between the results of different authors and different methods as for trends in the $F 2$-region parameters foF 2 and $h m F 2$. A trial to remove and/or explain some discrepancies between the results of six different authors/teams on trends in $f o F 2$ was done by
Laštovička et al. (2006b) via comparison of the results of their different methods obtained with a high-quality test data set (1976-1996, two comparable solar cycles) from Juliusruh (northern Germany). The need for a very careful correction for the solar cycle effect was pointed out. The correction for the solar cycle effect with $F 10.7$ or $E 10.7$ was evidently better than that with $R$ or $R 12$. Various regression-based methods used by five teams provided comparable weak negative trends in $f o F 2$. A Chilean team analyzed data with regression-based and wavelet-based methods and got quite different results of opposite sign. As shown by Laštovička 
et al. (2008b) there was however an error in the wavelet-based method. Also Chinese neural network-based method provided results comparable with regression-based results (Laštovička et al., 2008b). Only the foF 2 trends derived from Mikhailov's method, which uses a special way of eliminating geomagnetic activity effects, are substantially different from other results; however he claims that without his special elimination of the geomagnetic activity effects, the results are consistent with others. The main sources of discrepancies in trend results seem to be different data sets, quality of data, and different periods under analysis.

As the geomagnetic activity may influence ionospheric trends a new approach has been developed by De Franceschi et al. (1999) and Alfonsi et al. (2002, 2008) using a special magnetic activity catalogue for ionospheric applications (MACap). With this catalogue foF2 data have been isolated for quiet geomagnetic conditions. The derived foF 2 trends with these data for mid and high latitude stations at the southern hemisphere are generally negative and markedly stronger over Antarctica. This strong negative trend may be connected with the excursion (or possible inversion) of the geomagnetic field as the geomagnetic field weakening seems to be faster there than over the rest of the globe (De Santis, 2007). The information content of the foF 2 monthly median values derived from several ionosonde stations at high southern latitudes is shown in fig. 2 . The derived time scale $T_{\mathrm{k}}\left(T_{\mathrm{k}}=1 / K\right.$ is a kind of memory time after which the system behavior cannot be longer predicted) of about 500 years is comparable with that obtained from geomagnetic secular variations over Antarctica.

The $h m F 2$ trends have controversially been discussed. Considering the worldwide $h m F 2$ trend sign distribution more positive trends have been derived inside continental areas and more negative trends at ionosonde stations near seashores. According to Bencze (2007), nonmigrating tides may be responsible for this geographical distribution of $h m F 2$ trends. Such geographical distribution of nonmigrating tides in meridional wind has been confirmed by satellite observations (experiment HRDI onboard of UARS).
Bencze (2005) analyzed long-term trends in the $F$-region thickness $\left(h m F 2-h{ }^{\prime} F\right)$ and deduced a thermospheric cooling from the negative trend in the $F$-region thickness. This result is consistent with the thermospheric cooling indirectly detected by decreasing upper thermospheric density (e.g., Emmert et al., 2004; Laštovička et al., 2008a).

Ionospheric trends in the $E$ - and $F 1$-regions have been derived from different, globally distributed ionosonde stations. The estimated mean global trends show some general behaviour (positive trends in $f_{O} E$ and $f o F 1$, negative trend in $h^{\prime} E$ ) which can at least qualitatively be explained by an increasing atmospheric greenhouse effect (Bremer, 2008). However the experimental trends are stronger than the model results. Decreasing ozone values may reduce this inconsistency.

As predicted by model calculations (e.g., Akmaev et al., 2006; Bremer and Berger, 2002), long-term changes in the stratospheric ozone content should influence also trends in the meso- and thermosphere. These predictions have been confirmed by means of ionospheric reflection height data in the $L F$ range and $f o E$ data series observed at different stations around the world (Bremer, 2008; Bremer and Peters, 2008). Additionally it was demonstrated that the longitudinally dependent ozone trends are also closely related to similar variations in the foE trends (Bremer and Peters, 2008).

Based on analyses of foF 2 and $h m F 2$ longterm variations (Danilov and Mikhailov, 1999; Mikhailov and Marin, 2000; Marin et al., 2001) of Eurasian ionosonde stations the so called geomagnetic control concept has been developed by Mikhailov (2002). Initially formulated for ionospheric F2-layer parameters, later it was extended for the $f o E$ (Mikhailov and De la Morena, 2003; Mikhailov, 2006) and $f o F 1$ (Mikhailov, 2008) long-term variations. According to this concept the observed long-term variations of electron concentration in the whole ionosphere $(F 2, F 1$, $E$-layers) are mainly controlled by the geomagnetic activity long-term variations (11-year running mean $\mathrm{Ap}$ indices $\mathrm{Ap}_{132}$ are used). The revealed morphological pattern can basically be explained by the storm mechanisms both in the $F$ and $E$ regions in the framework of the contempo- 


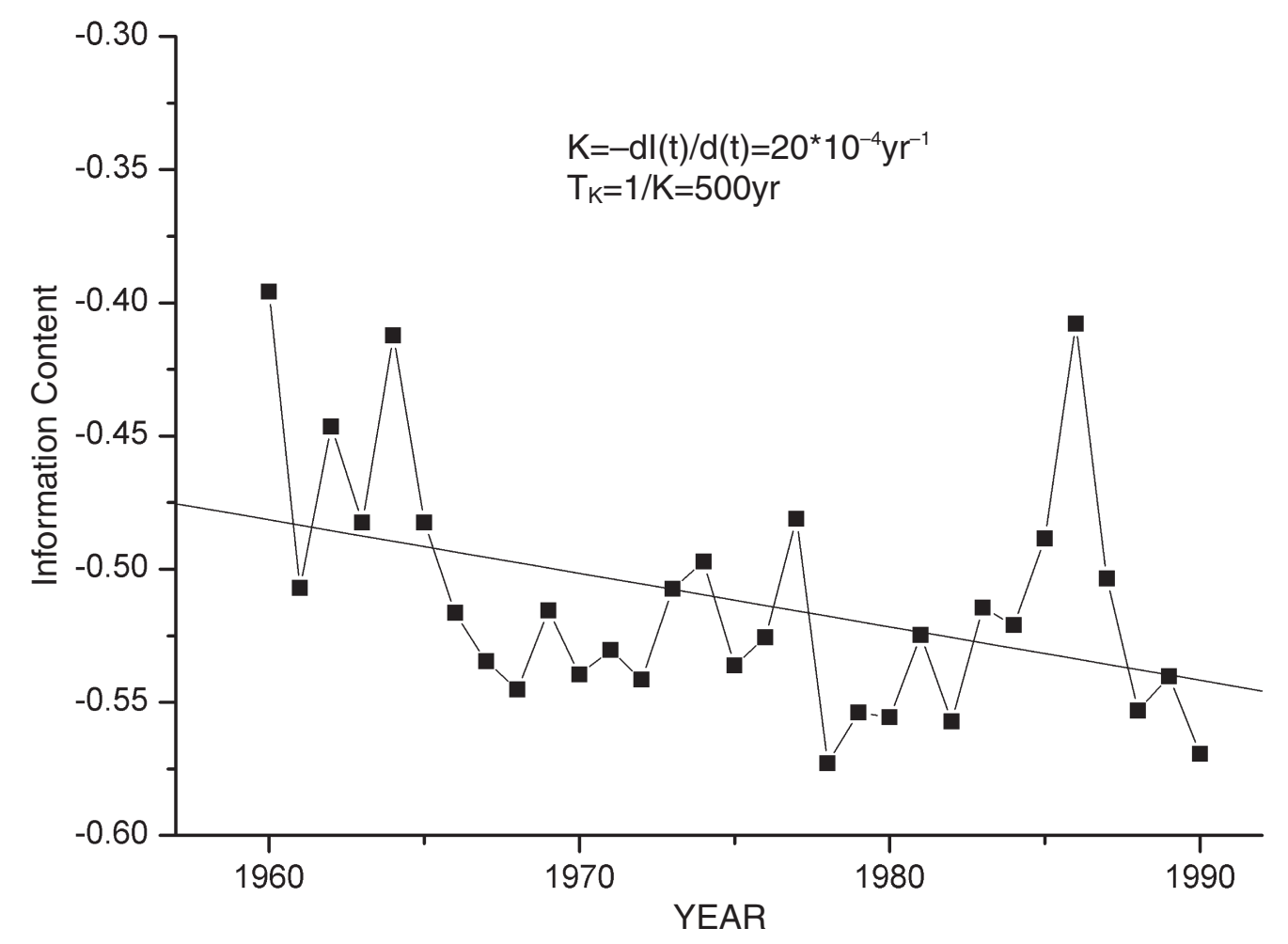

Fig. 2. Information Content applied to $f o F 2$ monthly medians from a set of stations at high southern latitudes in dependence on time. The time scale $\mathrm{T}_{\kappa}$ of about 500 years is comparable with that obtained for the geomagnetic secular variation over Antarctica (Alfonsi et al., 2008).

rary theory of the Earth ionosphere formation. The long-term trend in the ionosphere might be of geomagnetic origin due to a very long-term (centennial) increase in geomagnetic activity in the 20th Century (Clilverd et al., 1998; Mursula and Martini, 2006).

The most obvious effect of the geomagnetic control can be seen in the long-term variations of the critical frequency relative deviations. Figure 3 presents an example for Slough (Chilton) and Rome stations. Increasing geomagnetic activity corresponds to negative trends in $\delta f o F 2=\left(f o F 2_{\text {obs }}-f o F 2_{\text {reg }}\right) / f o F 2_{\text {obs }}$, $\delta f o F 1$ and $\delta f o E$ and viceversa. However, this geomagnetic control was fully valid only in the past. In the $E$ region the geomagnetic control broke down around 1970 (Mikhailov and de la Morena, 2003); fig. 3 reveals years 1972 for Slough and 1967 for Rome. Figure 3 also shows continuous loss of geomagnetic control of $f_{o} F 1$ in the 1990s and indicates possible beginning of its loss in foF 2 around 2000. This all is coincident with Laštovička's (2005) finding that the greenhouse gas control of long-term changes in the atmosphere-ionosphere system was increasing throughout the 20th Century, while the solar and geomagnetic control was decreasing.

Basically the geomagnetic control is carried out by well-known thermosphere storm mechanisms resulting from the auroral heating. Daytime $F 1$ and $F 2$ layers are closely related via neutral composition and temperature variations 

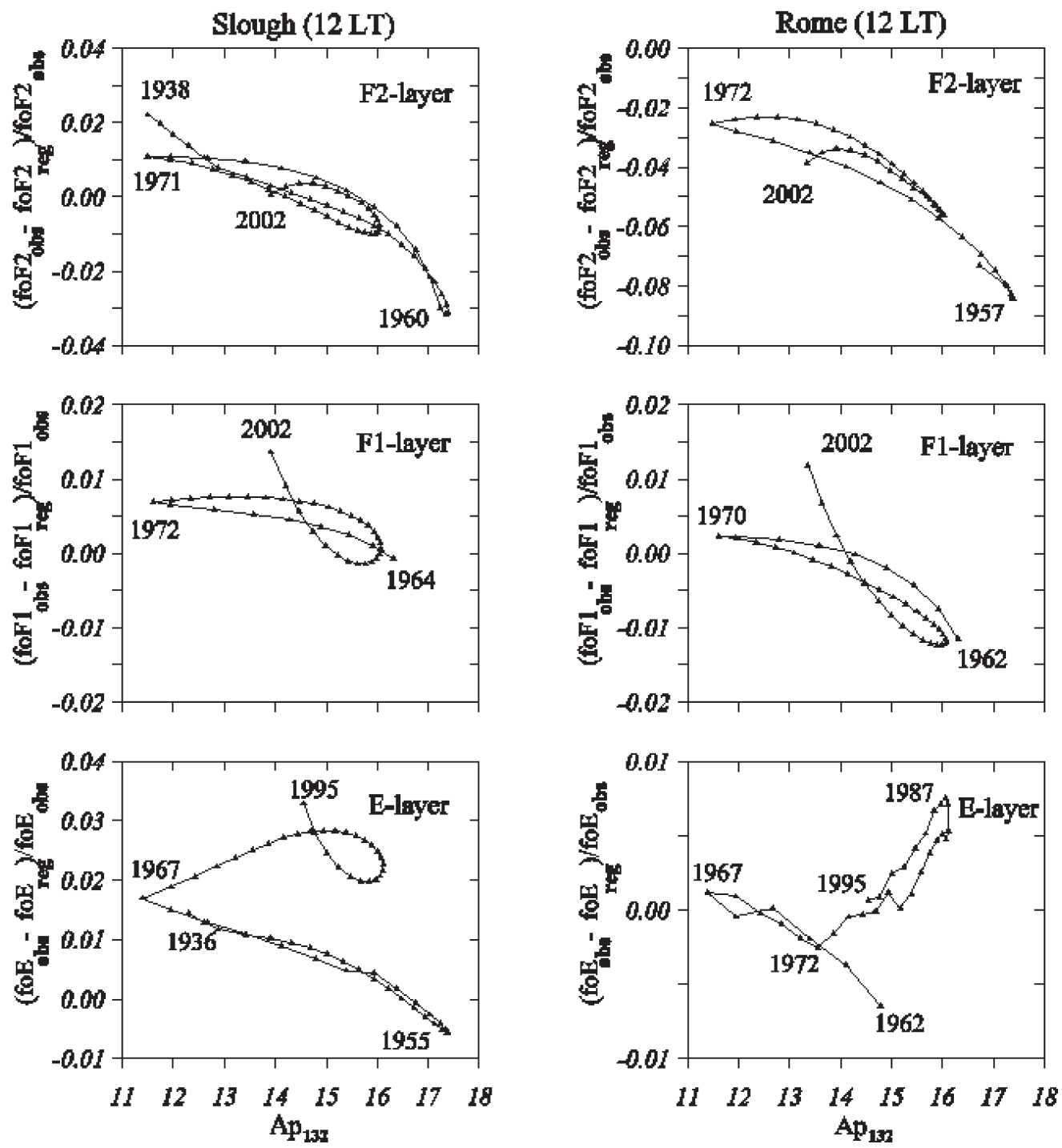

Fig. 3. Relationships between $\delta f o F 2, \delta f o F 1$, and $\delta$ foE and $A_{132}$ variations for Slough and Rome. Notice that the change in the type of the dependences appeared earlier in the $E$-layer and later in the $F 1$ and $F 2$-layers.

which strongly control ion composition at these heights (Mikhailov and Schlegel, 2003), the scheme of photo-chemical processes being mainly the same in both regions. The $\mathrm{O} / \mathrm{N}_{2}$ ratio may be considered a controlling parameter (Prölss, 1995) of the storm effects in the mid- latitude $F$-region. The $F 1$-region is fully controlled by photo-chemical processes, while thermospheric winds strongly affect the $F 2$-region compensating to some extent the neutral composition variation effects. Disturbances in the mid-latitude $E$-region are known to be relat- 
ed to [NO] variations (Ivanov-Kholodny and Nusinov, 1979), which control the $\left[\mathrm{NO}^{+}\right] /\left[\mathrm{O}_{2}{ }^{+}\right]$ ratio and via the effective dissociative recombination coefficient it changes the $E$-layer electron concentration. The dependence of $[\mathrm{NO}]$ on auroral activity observed not only at high but at middle latitude as well (Ridley et al., 1999; Barker et al., 2001) can explain the background geomagnetic control of the $f o E$ long-term variations (Mikhailov, 2006).

Low-frequency drift measurements at Collm can be used to derive long-term trends in some wind parameters near about $90 \mathrm{~km}$ altitude (Jacobi and Kürschner, 2006). Semidiurnal tidal amplitudes have decreased (see also Jarvis, 2005), possibly in connection with stratospheric ozone decrease. Gravity wave analyses (0.7-3 h period interval) based on mesospheric LF wind observations at Central Europe revealed no trend, but a possible impact of the solar cycle was found, which could be supported by model results (Jacobi et al., 2006).

\section{Atmospheric waves and the ionosphere}

Forcing of the ionosphere and upper atmosphere by atmospheric waves (planetary, tidal, gravity and infrasonic waves) mostly from the troposphere and stratosphere is the primary factor in coupling of the ionosphere from below. This forcing plays an important or even dominant role in the variability of the ionosphere under quiet geomagnetic/magnetospheric and solar conditions. Since such a forcing is hardly predictable at present, it is a main source of uncertainties of ionospheric predictions. Therefore, better knowledge of atmospheric wave characteristics, variability, predictability and ionospheric impact is desirable. For a brief overview see Laštovička (2006). COST 296 community concentrated on investigating the ionospheric impact of planetary, gravity and infrasonic waves.

\subsection{Planetary waves}

Planetary waves propagate to the MLT region heights, but their direct propagation well into the ionosphere is impossible due to atmospheric viscosity (e.g., Laštovička, 2006). They can propagate upwards only indirectly via modifying an upward propagating agent like tidal or gravity waves, or vertical drifts. Moreover, the planetary wave type oscillations in the $F 2$ region are caused partly by planetary waves, partly by similar oscillations in geomagnetic activity (Altadill and Apostolov, 2003). However, details of this process are widely unknown thus making predictions of planetary wave forcing of the ionosphere almost impossible.

One of the most pronounced phenomena in the stratosphere is the sudden stratospheric warming. During the final stratospheric warming of the winter of 2003/2004, a 6-11-day oscillations arising from the planetary wave activity in the lower atmospheric regions were observed over Ebro and Alma-Ata stations (Gordienko et al., 2007), thus indicating their largescale character. Such oscillations indicate the timing of the transition from the winter to the summer circulation.

Planetary wave-like events occur in bursts of activity, as seen in fig. 4 . The persistence of such bursts has been investigated by Laštovička et al. (2006c). They found that at middle latitudes the persistence in $f o F 2$ is almost identical over Europe, northern US and northern Japan, typically 4-5 wave cycles for $\sim 5$-day waves, 3 3.5 wave cycles for $\sim 10$-day waves, and no more than 3 wave cycles for $\sim 16$-day waves. The persistence in the lower ionosphere is quite similar, but coincidence with events in $f o F 2$ is poor.

Using meteor radar observations at Collm long-period oscillations have been derived in the mesopause region that are known to be typical for planetary waves. The upper panel of fig. 5 shows running amplitude spectra of meridional winds for an altitude of $88 \mathrm{~km}$. Well visible is a regular quasi 2-day wave in summer, a more irregular 5-7 day signature, and long-period oscillations in winter. Note that very long periods (more than 20 days) generally appear in late winter only; they are connected with stratospheric warmings and usually lead to temporary cooling in the upper mesosphere. This is shown in the lower panel of fig. 5 (updated from Jacobi et al., 2007), which presents bandpass filtered meridional wind and temperature 

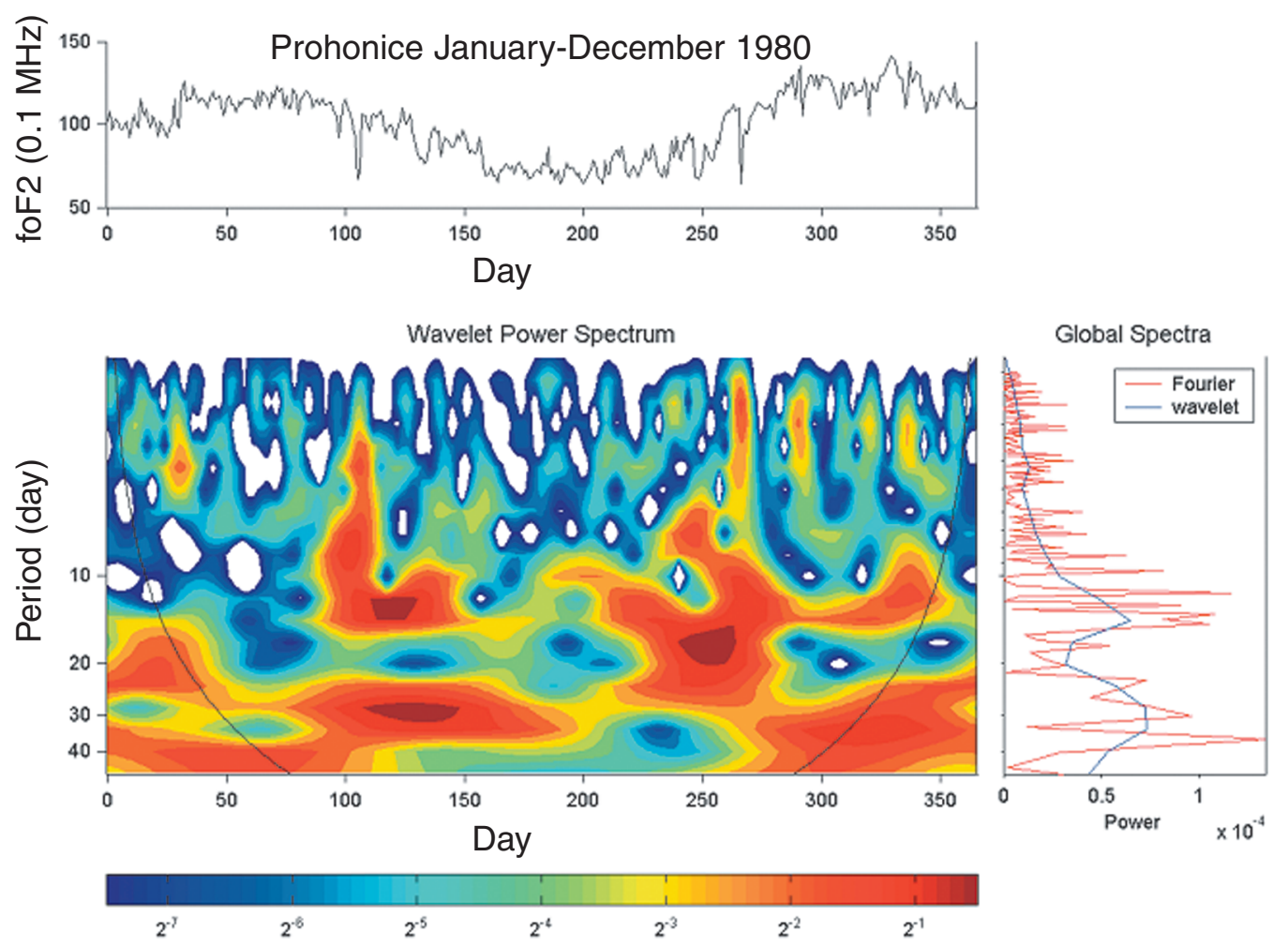

Fig. 4. Planetary wave activity inferred from $f o F 2$ for Průhonice, January-December 1980, Top panel: time series of raw foF 2 data. Bottom left panel: wavelet transform power spectrum of the planetary wave activity. Power spectrum is normalized to 1. Bottom right panel: global (over 365 days) Wavelet and Fourier spectrum.

measured by the radar. It can be seen that during times of large wind variability meridional winds and temperatures are correlated, i.e. southward (negative) winds are connected with lower temperatures as expected.

Planetary wave-type oscillations were observed even in the GPS TEC (total electron content). Comparison with stratospheric planetary waves in case studies showed that signatures of planetary waves occurred simultaneously in the middle atmosphere and ionosphere (Borries et al., 2007).

Whereas planetary waves cannot propagate to thermospheric/ionospheric heights, a more direct coupling at planetary time scales is observed between the neutral atmosphere and the lower $E$ region. It was shown a long time ago that the di- urnal cycle of $E$-region LF reflection heights is connected with the scale height, and thus temperature, of the upper mesosphere region. Jacobi et al. (2008) have shown that temperatures from meteor radar measurements and LF scale heights are, at least during winter, correlated at time scales of long-period oscillations. This demonstrates that the neutral atmosphere and lower ionosphere are coupled via planetary waves.

\subsection{Gravity waves}

There are three main categories of gravity waves and their ionospheric counterparts, travelling ionospheric disturbances (TIDs): (a) Large-scale waves excited in the auroral zone, 


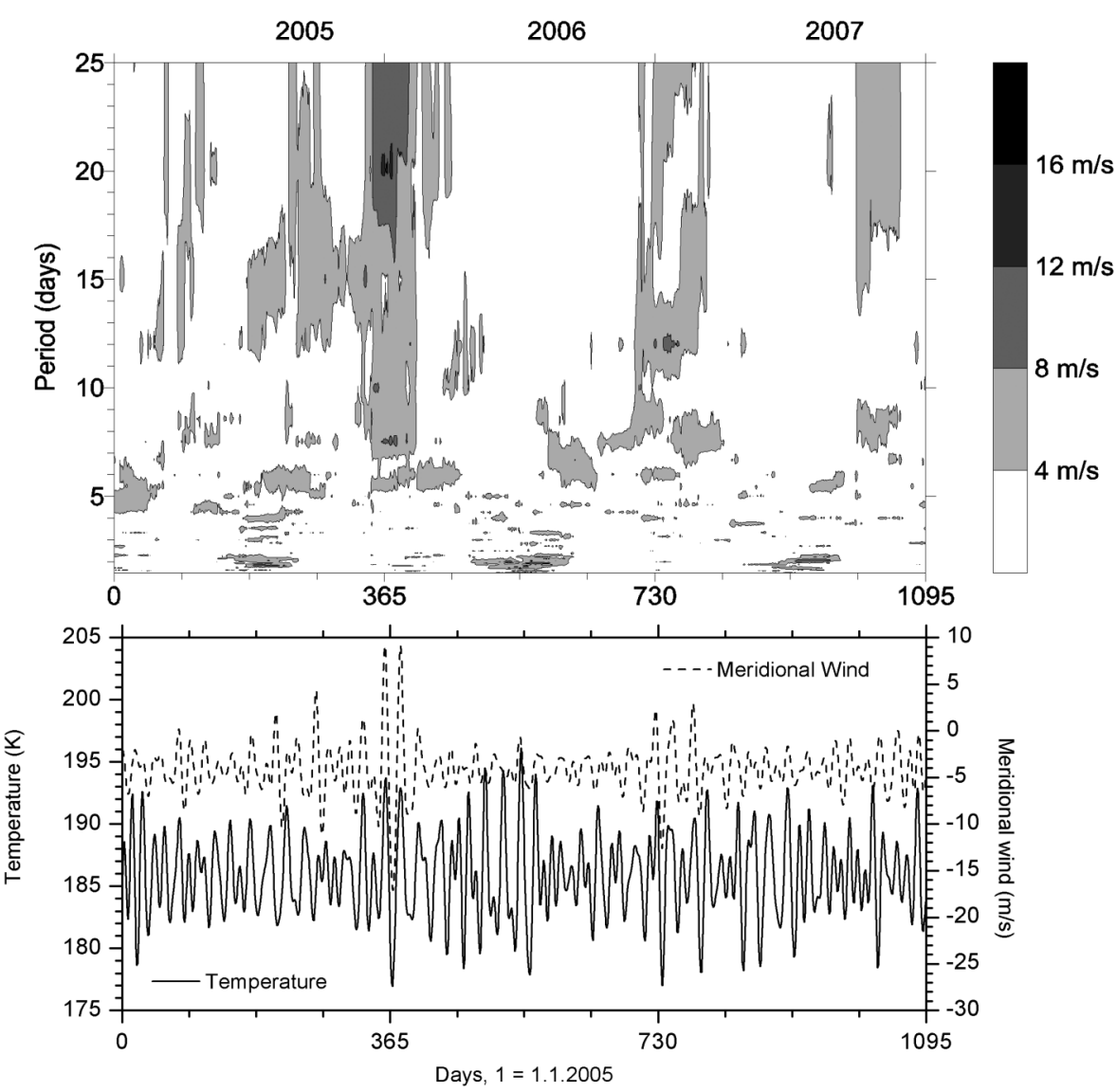

Fig. 5. Upper panel: Meridional wind amplitude spectra at $88 \mathrm{~km}$ altitude, measured with the Collm SKiYMET radar. Lower panel: 10-30 days bandpass filtered meridional wind at $88 \mathrm{~km}$ and temperatures at $90 \mathrm{~km}$.

the biggest being caused by geomagnetic storms. (b) Medium- and small-scale waves coming from atmospheric sources located mostly below the ionosphere. (c) Waves excited in situ, first of all by solar terminator and solar eclipses. COST 296 community focused investigations on gravity waves under (b) and (c).

Acoustic-gravity wave pulses have been detected using the data of the solar eclipse on 3 October 2005 and other events. The computer code for the two-dimensional (2-D) analysis of oscillations of electron density and determination of parameters of acoustic-gravity waves propagating through ionospheric plasma is available at the IAP Prague Web site at: http://www.ufa.cas.cz/html/climaero/sauli.html. The 2-D description is not sufficient for studying wave packets coming from below. Therefore, a 3-D version has been developed, which could utilize future high-quality Galileo-LEO $\mathrm{RO}$ electron density profiles for detecting and determining the 3-D structure of medium- and small-scale TIDs/gravity waves. This code is also available at the IAP Prague, but it is essentially unable to work with data of present-day quality and spatial-temporal coverage, data based on future fleet of GNSS satellites are required.

Šauli et al. (2006a) observed often wave-like bursts during quiet days in the electron concentration in the $F$ region over European middle lat- 
itudes, with a regular significant increase of oscillation activity after sunrise and another, less regular, increase in the vicinity of sunset; this is evidently an effect of solar terminator.

An analysis of generation of acoustic-gravity waves during solar eclipses reveals remarkable differences between total and partial eclipses both in characteristics of gravity waves propagating through the ionosphere and in formation and location of their source. Wavy phenomena were analyzed for the solar eclipses of 11 August 1999, 29 March 2006 and the annular eclipse of 3 October 2005 (Jakowski et al., 2008; Sauli et al., 2006b, 2007). The supersonic motion of Moon's cool shadow through the atmosphere generated atmospheric gravity waves, observed by ionospheric methods. According to the Ebro digisonde data analysis, the source region for eclipse of October 2005 was the lower thermosphere below about 180-190 $\mathrm{km}$ altitude; however, the gravity waves were not detected in TEC (Jakowski et al., 2008). Further investigations showed that the height interval of gravity wave excitation for solar eclipses does not differ much from heights where the solar terminator excites gravity waves; upper $F 1$ region or $F 1-F 2$ transition region. Effects of the annular solar eclipse on the ionospheric plasma at $F$ layer height are less pronounced compared to total eclipse effects, only signatures of bow shock wave are detected within plasma. Also spectral analysis shows lower energy in oscillations during annular eclipse (2005) compared to total eclipse events (1999, 2006). Annular solar eclipse seems to generate only gravity waves attributable to the propagating bow shock, not acoustic waves contrary to full eclipses (Šauli et al., 2007).

Results of gravity wave analyses from wind radars in the MLT are strongly dependent on system characteristics, for example, the wave periods seen by MF radars ( $>10 \mathrm{~min})$ and other systems (meteor radars, $<2 \mathrm{~h}$ or $>1 \mathrm{~h}$ depending on the method applied; LF drift measurements, $0.7-3 h$ ) are very different and results not necessarily comparable. The seasonal cycle of gravity waves has been shown on several occasions (Gavrilov et al., 2002; Jacobi et al., 2006). Usually, gravity wave amplitudes increase with height, except for the summer season where a decrease is found up to about $90-95 \mathrm{~km}$. Therefore, in the upper MLT a tendency towards a winter maximum is visible, while in the lower mesopause region a semiannual oscillation prevails (Jacobi et al., 2006).

Using time series of zonal wind variance (as a gravity wave proxy) a strong quasi-decadal variability could be detected which is possibly connected with the 11-year solar cycle through wave filtering in the mesosphere (Jacobi et al., 2006). The bandpass filtered variances for summer are anticorrelated with the zonal prevailing wind over Central Europe, i.e. weaker zonal prevailing winds are connected with stronger wave amplitudes as to be expected by a simple linear theory.

\subsection{Infrasonic waves}

After having been intensitively studied in the 1960s and 1970s, the influence of infrasonic waves (or infrasound or acoustic mode of acoustic-gravity waves) on the ionosphere was almost forgotten, but interest in ionospheric infrasound revived in the 2000s. They are not a dominant factor in the atmosphere-ionosphere coupling, but their role cannot be forgotten, and they are able to affect ionospheric circuits as a source of oscillations in the period range from seconds to a few minutes. A recent review has been published by Krasnov et al. (2006).

In the ionosphere, oscillations in the infrasound period range (seconds to a few minutes) may be caused either by infrasound or by geomagnetic micropulsations. The Czech Doppler measuring system was broadened to five measuring paths, and with the use of micropulsation measurements at the Budkov geomagnetic observatory it was possible to distinguish between oscillations caused by these two different sources. Waves with periods of about 1-3 min, if observed simultaneously on all five measuring paths of the Czech Doppler system, correlate with geomagnetic $P i 2$ pulsations, particularly with fluctuations of horizontal components of the geomagnetic field as one of space weather phenomena. Such waves are not infrasound; they are manifestations of micropulsations (Chum et al., 2009). On the other hand, when the observations of wavy features at five 

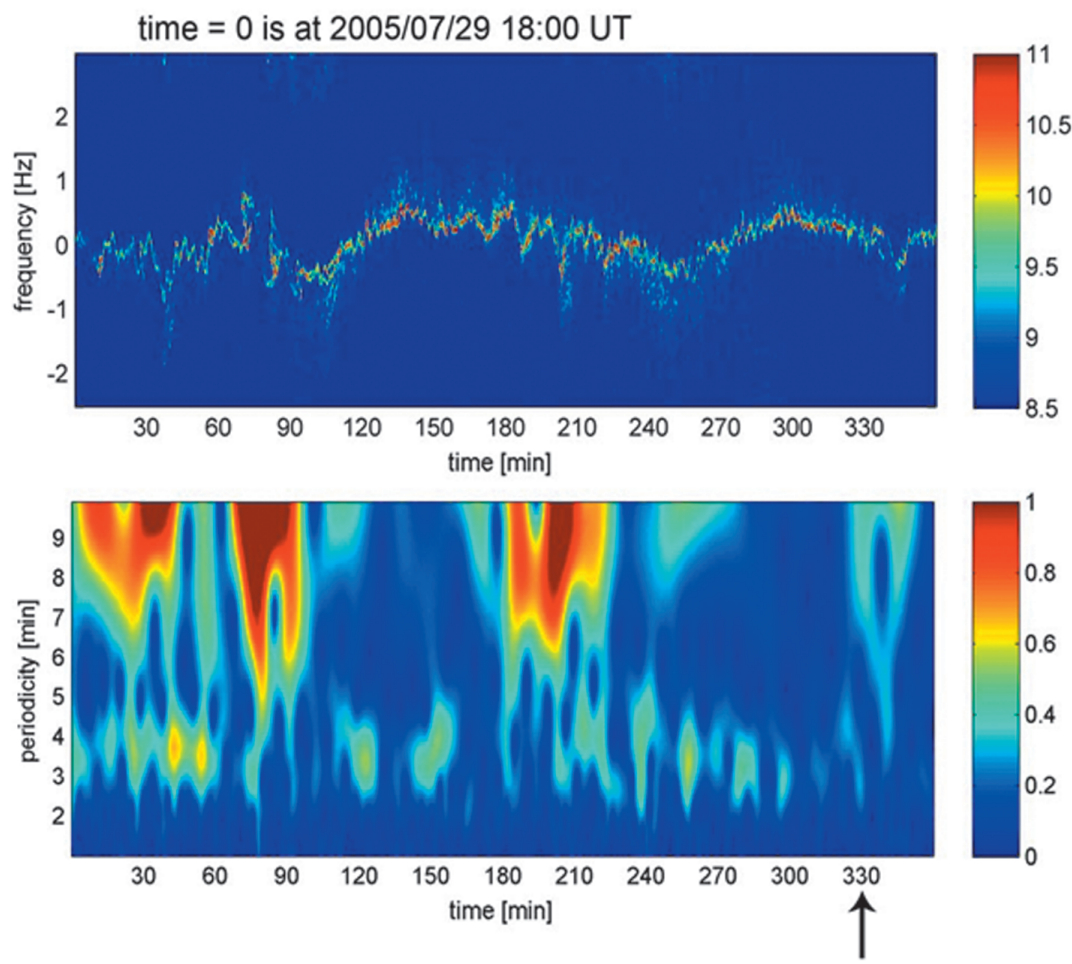

Fig. 6. Upper panel: Doppler shift spectrogram at the Panska Ves sounding path during convective storm activity on 29 July 2005, start time at 18:00 UT. Lower panel: Wavelet transformation of the signal, which shows clear activity at periods 3-4 min, not related to activity at longer periods (short-period gravity waves). Arrow denotes the approximate time of passage of the squall line of the storm under the ionospheric observation point.

measuring paths are evidently non-simultaneous, then they are not accompanied by micropulsations and their origin is infrasound.

The results show that infrasonic waves of tropospheric origin, which would accompany (strong) tropospheric convective storms, are not a typical ionospheric phenomenon in Central Europe. Infrasound was observed in the ionosphere only during two events of extreme tropospheric activity, very strong convective storm complex of late July 2005 and hurricane Kyrill of January 2007, while it was not observed during seven other «normal» convective storm events (Šindelářová et al., 2009). These two strong events showed dominance of Doppler spectra by infrasonic waves with periods of about 3-4 min, as illustrated by fig. 6 . This was expected and corresponds to previous results based on studies in the central part of the USA (e.g., Georges, 1973) that a particularly efficient source of infrasound are those storms, during which the heights of cloud tops reach the tropopause or above, as it was also the case for Central European event of July 2005.

Model calculations show that an infrasonic sinusoidal signal launched at or near the surface is destroyed by nonlinear processes during its upward propagation; it transforms into two, initial and final, impulses. The location of the «transformation region» depends on frequency; its height increases with decreasing frequency. The acoustic waves can heat the upper atmosphere, for example waves with period of 3 min generated by thunderstorms can heat the above-lying at- 
mosphere with a rate up to $\Delta T_{a}=48.5 \mathrm{~K} /$ day in the region $245-330 \mathrm{~km}$ and, thus, thermally affect the ionosphere (Krasnov et al., 2007).

Two peculiar types of phenomena have been observed on infrasound time-scales, $S$-shapes and oblique quasi-linear shape (QLS) traces (Chum et al., 2008). S-shapes occur predominantly near sunrise and sunset in relation to solar terminator. No well-pronounced seasonal variation of the $S$-shape phenomenon is observed in terms of the total number of the $S$-shape events per month. On the other hand, there is a pronounced seasonal variation of diurnal distribution of the $S$-shape events, which is closely related to the sunset times as they change with seasons. As for QLS events, they are rare, mostly occuring in early night or in the late evening. They have quasi-linear shape in the frequencytime space with both negative and positive slopes, and both signs of Doppler shift. A typical QLS has a frequency span around $10 \mathrm{~Hz}$, duration of about $20 \mathrm{~s}$ and a slope of about 0.4-0.5 $\mathrm{Hz} / \mathrm{s}$. Several potential sources of QLSs were excluded such as aircrafts, satellites, bolides, meteors, meteorites, thunderstorms, or geomagnetic storms, but their origin remains unclear.

\section{Ionospheric variability}

The variability is a permanent ionospheric and plasmaspheric feature and meaningful predictions can only have statistical character. Among the ionospheric community there exists an interest in knowledge and developing models of ionospheric variability. COST 296 community concentrated on investigation of this variability using observations of $f_{o F}$, TEC and slab thickness $\tau$ at different European stations, data of the electron density in dependence on height at a fixed ionosonde station as well as of variability not caused by geomagnetic activity ( $Q$-disturbances).

\subsection{Variability in foF2, TEC, and $\tau$}

The ionospheric variability is the deviation of the current ionospheric condition from their quiet state. Monthly-median conditions are assumed as the quiet state. The variability can be determined by the variation from day-to-day (or from hour-to-hour) for a given month, year and location (Kouris et al., 1998, 2006a).

Empirical models predict monthly median conditions and the variability can be introduced as a dispersion measure around the monthly median values. This is accomplished by determining an upper and a lower decile (or quartile) factor (Fotiadis and Kouris, 2006a). It is found that the bounds of variability in $f_{o F}$ and the MUF are 0.20 (in absolute value) for $90 \%$ of the monthly-time, depending of course on the location, season and time of the day. Regarding the propagation factor $M(3000) F 2$ and the $E$-layer critical frequency, the lower and the upper deciles are \pm 0.14 of the monthly median value for the former and \pm 0.10 for the latter, while the bounds in the within-the-hour variability of $f_{0 F} 2$ are \pm 0.12 of the hourly-daily value and less than \pm 0.05 in TEC except at sunrise and sunset (Kouris et al., 2006b); which means that the within-the-hour variability of TEC is negligible.

The day-to-day variability in TEC is greater than in $f o F 2$ and exhibits its higher values during the nighttime hours (Kouris, 2008). The upper and the lower limits of TEC variability have an average value over Europe $\left(35^{\circ}-60^{\circ} \mathrm{N}\right)$ circa 0.30 (in absolute value) for $90 \%$ of the monthly time during the daytime, but they are higher during nighttime reaching an average value of 0.40 (Kouris et al., 2006a). However, it should be noted that levels of TEC variability greater than 0.50 occur in each month but only for a few hours, and fall mostly between the values of 0.50 and 0.80 although they can reach values up to 1.20 and even higher. These last ones are rare and irregular and occur mainly during winter and equinoxes and after midnight, and in any location (Kouris, 2008). Figure 7 illustrates the frequencies that the levels 0.50 or 0.80 (in absolute value) of TEC variability are exceeded during 1999 and 2000 at different locations (Kouris et $a l ., 2008)$. It is evident that a very disturbed state occurs mostly in equinoxes including February and November, and that the variability depends on the solar activity and the location.

The slab thickness variability shows a similar pattern with that of TEC or of $f o F 2$ variability (Kouris et al., 2005) but seems to depend strongly on season (fig. 8) and local disturbed 

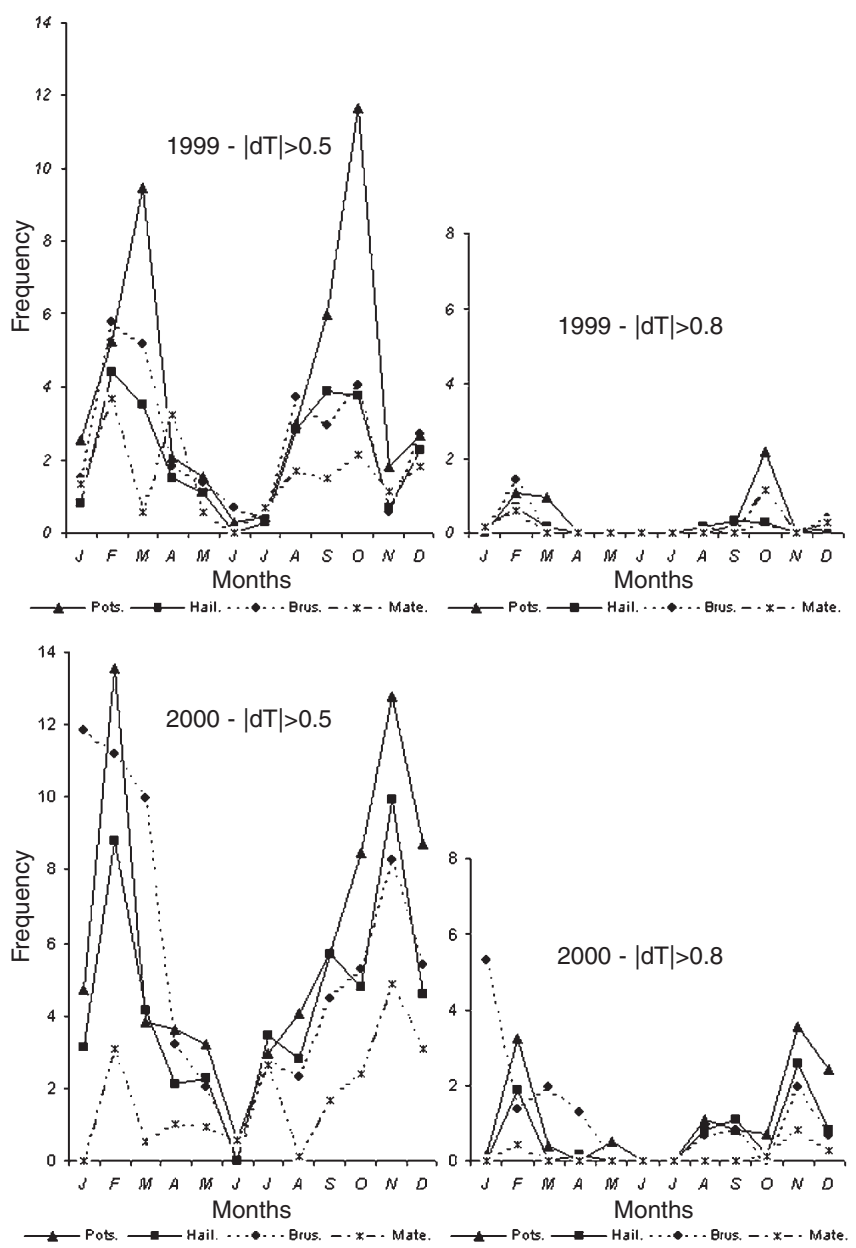

Fig. 7. Probabilities that the levels 0.50 or 0.80 of the relative deviations (in absolute value) of TEC are exceeded during 1999 and 2000 at four European locations.

conditions. The bounds in absolute value are 0.25 on average for the European region $\left(60^{\circ} \mathrm{N}\right.$ $-35^{\circ} \mathrm{N}$ ) for the daytime, while for the nighttime conditions they are 0.35 .

A simple $f_{0} F 2$ variability (quartiles) model as a function of the geomagnetic latitude is developed (Fotiadis and Kouris, 2006a) which is overall successful at midlatitudes (presenting an error of $3-4 \%$ in most cases), being though somewhat limited in the geographical regions of high variability such as the equatorial crest and the high latitude boundary. Furthermore, an analytical investigation on the climatology of foF 2 ionospheric disturbances (Fotiadis et al., 2004) has pointed out the morphology of longduration negative $f o F 2$ disturbances. Then, a model is developed which may complement and improve existing models (e.g. STORM IRImodel), being at the same time a directly operational non-conditional stand-alone model (Fotiadis and Kouris, 2006b).

Finally, it is worth mentioning that TEC and foF 2 are found to be highly correlated with solar activity and latitude, while the slab thickness 

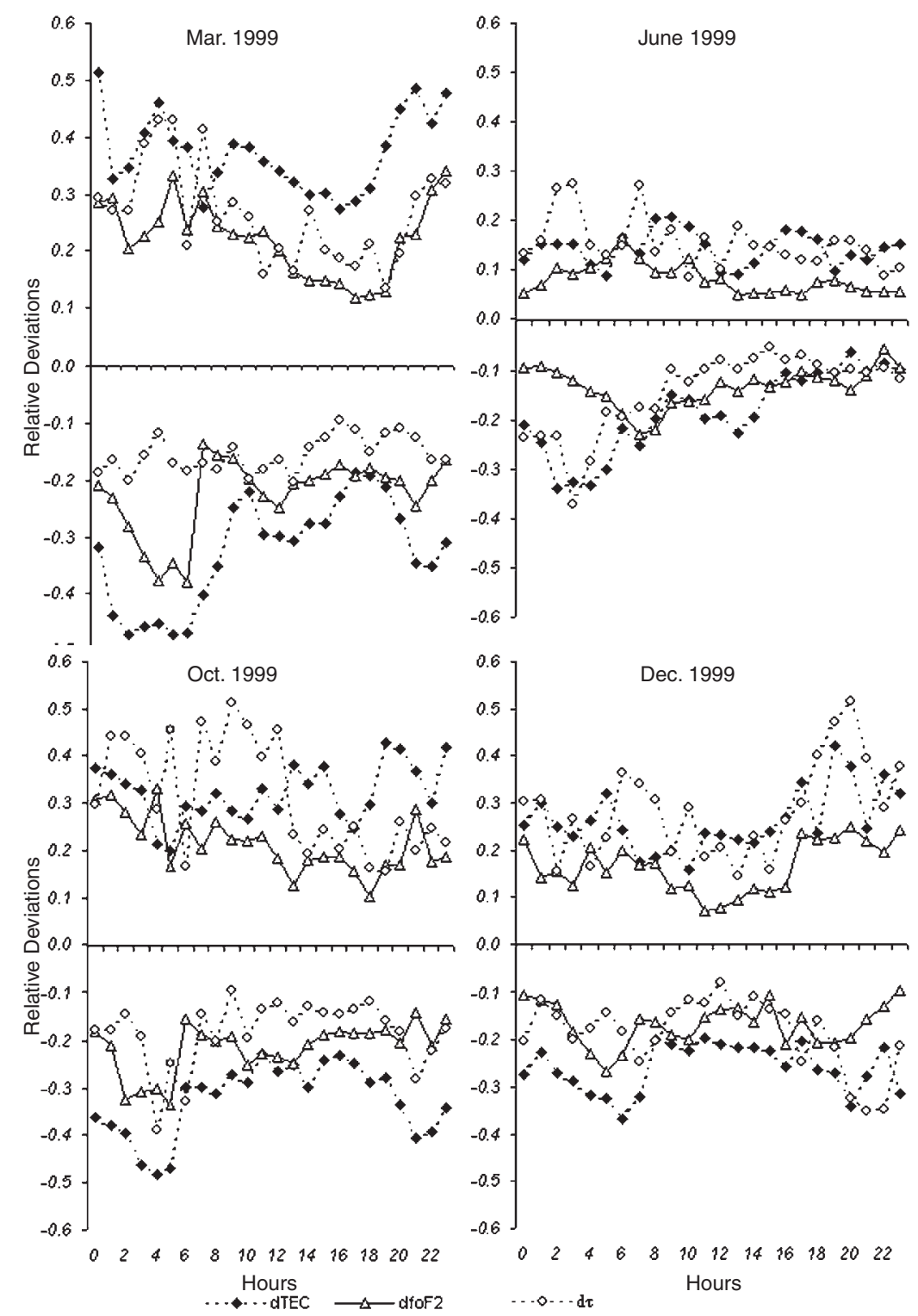

Fig. 8. Comparison of the Day-to-Day variability (Deciles) in TEC, $f \circ F 2$ and $\tau$ at different months in Hailsham.

is independent of both solar activity and latitude; and at the same time all the three characteristics are highly correlated with season (Kouris et al., 2008).

\subsection{Variability in dependence on height}

The continuous database of vertical incidence soundings from the Ebro Observatory 


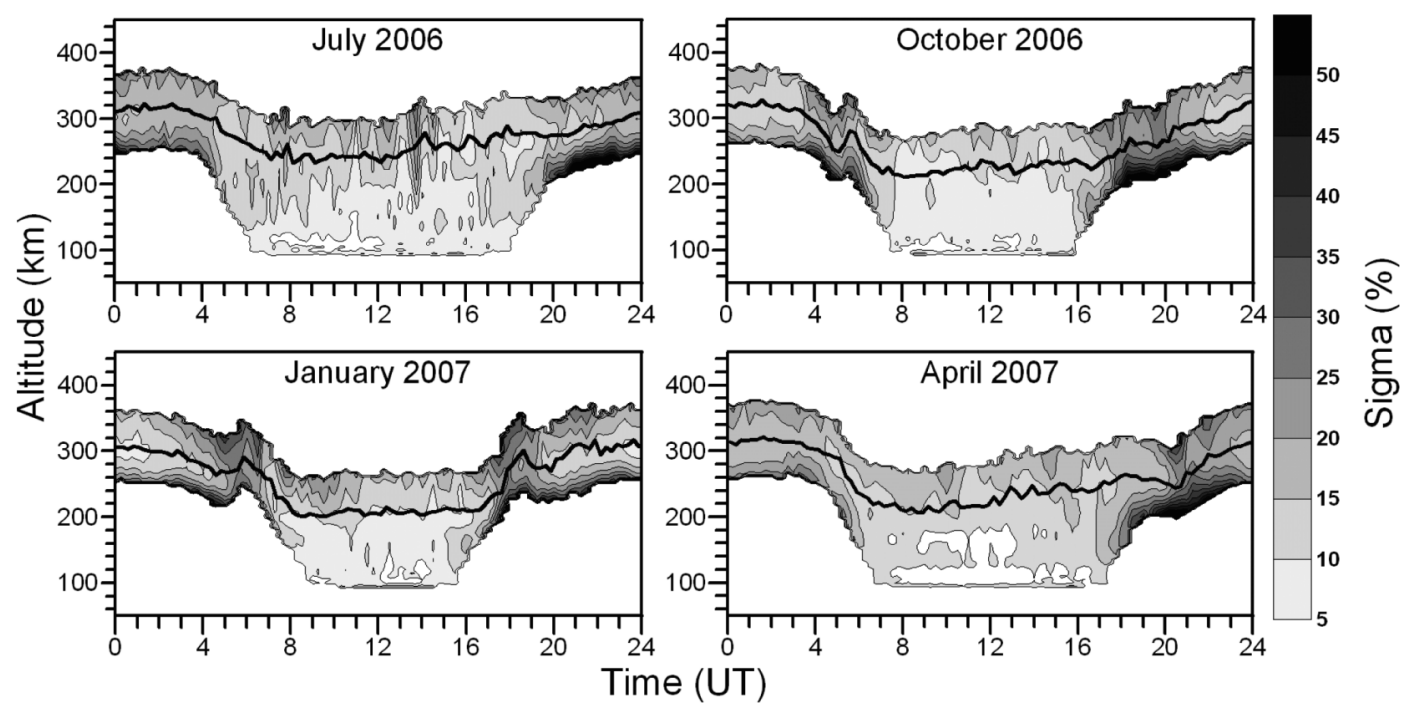

Fig. 9. Time-height cross-plots of the daily pattern of the variability in terms of percentages $\sigma \mathrm{p}(\mathrm{h})$ for indicated months above Ebro station (Altadill, 2007).

$\left(40.8^{\circ} \mathrm{N}, 0.5^{\circ} \mathrm{E}\right)$ during the time interval from 1995 to 2005 has been used in order to obtain the typical time/altitude variability of the ionosphere from the daily pattern of the electron density profiles $\mathrm{N}(\mathrm{h})$ at a mid-latitude station over Europe in terms of «standard deviation». Results of daily, seasonal, and long-term pattern of $\mathrm{N}(\mathrm{h})$ variability are interpreted in terms of solar and geomagnetic activity, «meteorological influences» from below and in terms of potential modeling results (Altadill, 2007). The results indicate that the main temporal variations of the variability $\sigma \mathrm{p}(\mathrm{h})$ (ratio of the standard deviation and mean values of the plasma frequency in per cent; daily, seasonal and longterm) depend of height and of local time. The variability of the $F$-region above Ebro station has the behavior shown in fig. 9 .

The $\sigma \mathrm{p}(\mathrm{h})$ decreases with height from the bottom of the $F$-region up to $h m F 2$ during nighttime and it increases with height during daytime. The variability at around $h m F 2$, $\sigma \mathrm{p}(h m F 2)$ is larger by night ( $15 \%$ in average) than during daytime $(11.5 \%)$. The larger variability occurs at the base of the $F$-region, $\sigma \mathrm{p}(\mathrm{hB})$, during nighttime, with typical values of
$30-40 \%$. The daytime values of $\sigma \mathrm{p}(\mathrm{hB})$ are very low with about $5 \%$. The $\sigma \mathrm{p}(\mathrm{hB})$ is larger from dusk to midnight, $\sigma \mathrm{p}(\mathrm{hB}, \mathrm{DM}) \sim 34 \%$, than from midnight to dawn, $\sigma \mathrm{p}(\mathrm{hB}, \mathrm{MD}) \sim 27 \%$. There is no significant long-term dependence of the $\sigma \mathrm{p}(h m F 2)$ with neither the sunspot activity nor the geomagnetic activity. The long-term behavior of $\sigma \mathrm{p}(\mathrm{hB})$ does depend on local time. The $\sigma \mathrm{p}(\mathrm{hB}, \mathrm{MD})$ increases with increasing sunspot activity from $\sim 18 \%$ at solar minimum to $\sim 32 \%$ at solar maximum whereas the $\sigma \mathrm{p}(\mathrm{hB}, \mathrm{DM})$ has no significant solar cycle dependence, despite a weak trend of increasing background values (winter season) with sunspot activity from $\sim 23 \%$ at solar minimum to $\sim 30 \%$ at solar maximum (fig.10). The yearly pattern of $\sigma \mathrm{p}(h m F 2)$ has a clear annual variation, which depends on local time. Whereas the nighttime pattern of $\sigma \mathrm{p}(h m F 2)$ maximizes during winter $(\sim 15 \%)$ and reaches a minimum during summer $(\sim 13 \%)$, the daytime pattern of $\sigma \mathrm{p}(h m F 2)$ minimizes during winter $(\sim 10 \%)$ and maximizes during summer $(\sim 12 \%)$. The yearly pattern of $\sigma \mathrm{p}(\mathrm{hB})$ depends on both local time and solar activity. Both $\sigma \mathrm{p}(\mathrm{hB}, \mathrm{DM})$ and $\sigma \mathrm{p}(\mathrm{hB}, \mathrm{MD})$ display a semiannual variation and they maximize 


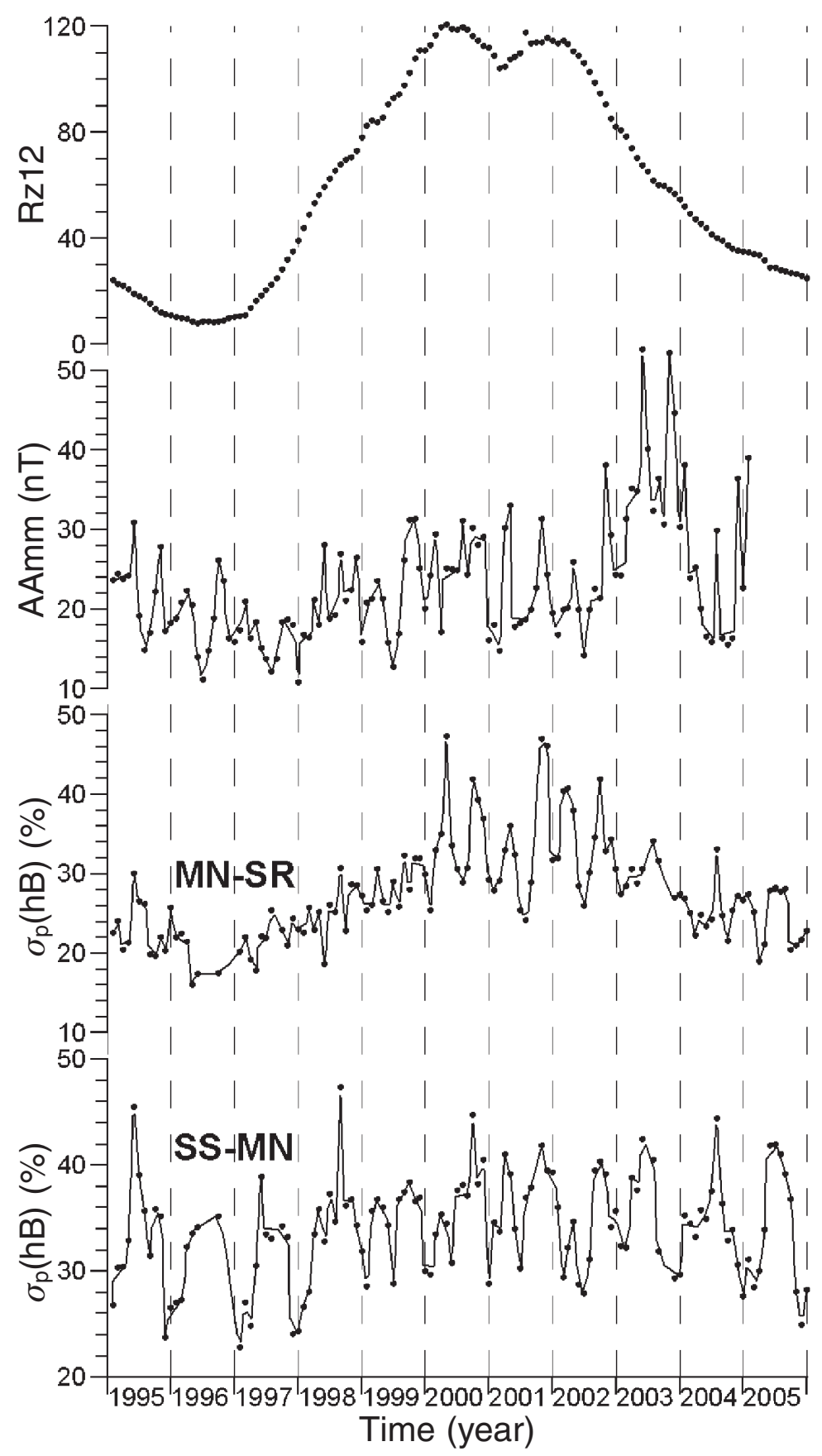

Fig. 10. Long-term dependence of the $\sigma \mathrm{p}(\mathrm{h})$ from 1995 to 2005 . From top to bottom: yearly smoothed monthly means of sunspot numbers Rz12, yearly smoothed monthly means of geomagnetic activity index AA, average of $\sigma \mathrm{p}(\mathrm{h})$ from midnight to sunrise (MN-SR), and from sunset to midnight (SS-MN) respectively (Altadill, 2007). 

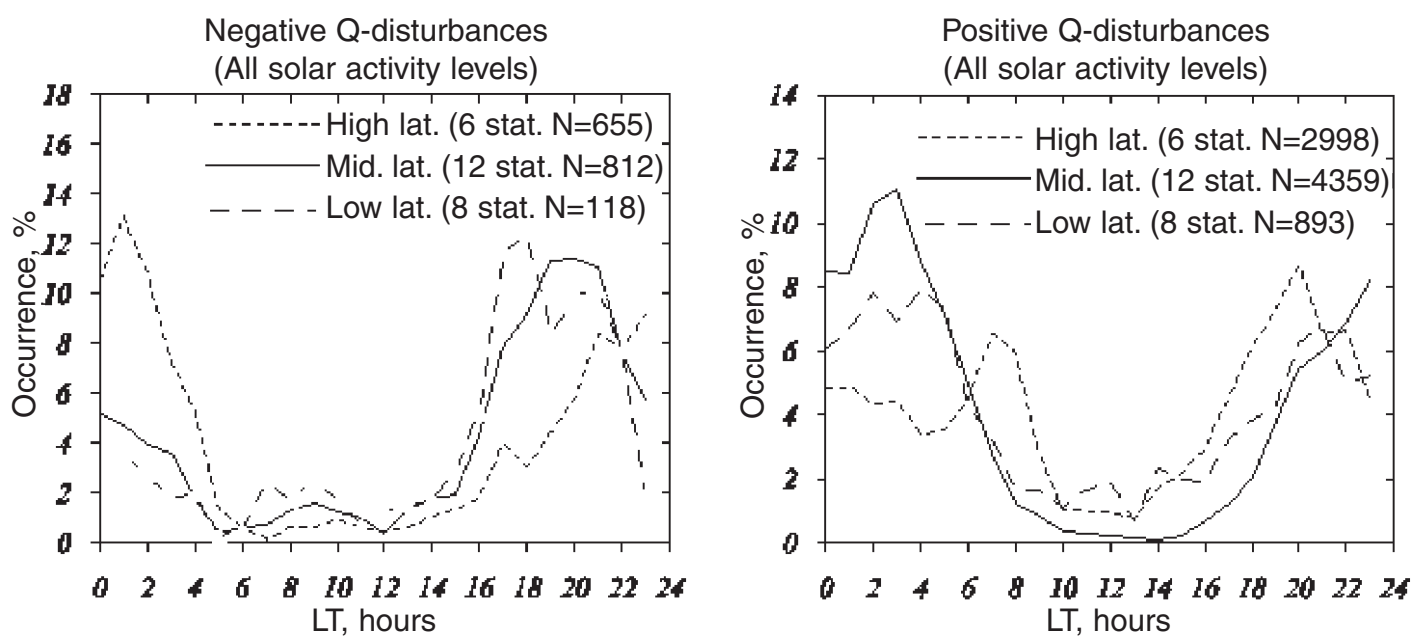

Fig. 11. Occurrence of negative and positive $Q$-disturbances versus local time for high, middle, and lower latitude stations. Total number of stations and events are given in brackets.

during equinoxes $(\sim 38 \%)$ and minimize during solstices $(\sim 30 \%)$ for years of high-solar activity. However, $\sigma \mathrm{p}(\mathrm{hB}, \mathrm{DM})$ displays an annual variation for years of mid- to low-solar activity, where it maximizes during summer $(\sim 37 \%)$ and minimizes during winter $(\sim 30 \%)$, while there is no clear yearly pattern for $\sigma \mathrm{p}(\mathrm{hB}, \mathrm{MD})$. The above seasonal and solar pattern of variability was modeled using a simple formulation (Altadill et al., 2008).

\subsection{Quiet time F2-layer disturbances}

Traditionally ionospheric F2-layer disturbances are related to solar activity variations (geomagnetic activity being a part of it), but there exists a large class of disturbances (both positive and negative) which are not directly caused by geomagnetic activity ( $Q$-disturbances). Their amplitudes are comparable with the amplitudes of moderate F2-layer storm effects, they exhibit different global morphology, and their formation mechanisms are also different from those of usual F2-layer storms.

The main morphological analysis was made with data of 26 ionosonde stations located in the
Eurasian sector. As the morphology of $Q$-disturbances depends on latitude, all stations have been divided for high-latitude (6 auroral and sub-auroral stations), mid-latitude (12 stations), and lower latitude (8 stations). A 27-day foF2 running median centered for the day in question rather than usual monthly median was used for the $Q$-disturbance analysis. $Q$-disturbances were referred to hourly deviations $\left(N_{\mathrm{m}} F 2 / N_{\mathrm{m}} F 2_{\text {med }}-1\right)$ more than $40 \%$ if all 3-hourly geomagnetic ap indices were $\leq 7$ for 24 previous hours. Three levels of solar activity were considered using 12-monthly running mean sunspot numbers: solar minimum $\mathrm{R}_{12}<50$, medium $\mathrm{R}_{12}=50-100$, and maximum $\mathrm{R}_{12}>100$.

The following morphological pattern of $Q$ disturbances was revealed (Mikhailov et al., 2004; Depueva et al., 2005):

1) Positive $Q$-disturbances are more numerous than negative ones at all latitudes in question and at any level of solar activity.

2) Both types of disturbances are more numerous (by 2 times) at solar minimum.

3) The percentage of long duration (both negative and positive) $Q$-disturbances increases with latitude.

4) Both types of disturbances are most fre- 
quent in the evening and night-early-morning LT sectors, and they are rare during daytime (fig. 11).

5) Negative disturbances cluster around winter months (Nov-Jan) for all solar activity levels. The occurrence probability is small for other seasons.

6) Seasonal variation pattern for positive $Q$ disturbances is more complicated and less systematic compared to the negative $Q$-disturbance cases, indicating that some processes contribute to their formation and their efficiency vary with geophysical conditions.

7) Positive $Q$-disturbances exhibit mostly latitudinal variations for the amplitude, the latter increasing with latitude. On the contrary, the negative disturbances demonstrate mainly longitudinal variations with the amplitude slightly varying with latitude.

8) Longitudinal variation of $Q$-disturbances looks like a planetary wave with zonal wave number $\mathrm{m}=1$. The front of this wave may be very steep or gently sloping. The peak moves back and forth in its day-to-day variations.

9) There is a difference between the European and American sectors - the disturbance effect is less pronounced in the western hemisphere, although the number of stations is not sufficient for a final conclusion.

\subsection{Physical interpretation of ionospheric $Q$-disturbances}

The analysis of the daytime (11-14 LT) observations of $N m F 2$ and $N m E$ at sub-auroral and midlatitude stations for periods of positive and negative F2-layer Q-disturbances showed a synchronous type of the $\delta N m F 2$ and $\delta N m E$ variations. Therefore, for negative $Q$-disturbances in the F2-layer we have negative deviations in the E-layer and positive F2-layer disturbances are accompanied by positive deviations in $N m E$. The only mechanism able to explain these variations is vertical motion which changes the effective scale height $\mathrm{H}\left(\mathrm{O}_{2}\right)$ of the molecule oxygen distribution at $E$-region heights. The neutral gas downwelling enriches the thermosphere with atomic oxygen at $F 2$ layer heights and decreases $\mathrm{H}\left(\mathrm{O}_{2}\right)$ in the $E$-region to result in a synchronous $N m F 2$ and $N m E$ increases. The upwelling of the neutral gas should cause an opposite effect.

The expected variations of atomic oxygen during F2-layer $Q$-disturbance events were confirmed by Millstone Hill ISR observations (Mikhailov et al., 2007a). Using a self-consistent approach to the $N_{\mathrm{e}}(\mathrm{h})$ modeling at $F 2$-region it could be shown that the positive and negative $Q$-disturbances in the $F 2$-region are mainly due to the atomic oxygen concentration variations. Negative disturbances correspond to low concentration of atomic oxygen and strong poleward neutral wind. The opposite situation takes place for the positive $Q$ disturbances.

However, some morphological features of the negative $Q$-disturbances cannot be explained by the neutral gas upwelling. Therefore, an idea of the ground state of the thermosphere was proposed. It corresponds to a very low geomagnetic activity with a solar-driven thermospheric circulation characterized by relatively strong daytime poleward wind and relatively low atomic oxygen concentrations at middle and sub-auroral latitudes.

Negative $Q$-disturbances occur under the ground state of the thermosphere. The clustering of the negative $Q$-disturbances around winter solstice is related to the poleward wind which is the strongest under such conditions. The occurrence of negative $Q$-disturbances depends on the $N m F 2$ median level. If the month is geomagnetically disturbed with usual negative F2-layer storm events, the $N m F 2$ median level is lower and this prevents appearance of the negative $Q$-disturbances. On the contrary, negative $Q$-disturbances should appear if a month is quiet and the $N m F 2$ median level is relatively high.

Positive $Q$-disturbances appear under slightly enhanced auroral activity when the high-latitude heating increases and damps the solar-driven poleward thermospheric circulation. The tendency of the high- and middle-latitude positive $Q$-disturbances to cluster around equinoxes can be related to the enhanced geomagnetic activity during this time. Further details concerning $Q$-disturbances and their differences to storm-induced events can be found in Mikhailov et al. (2007b). 


\section{Space weather impacts on the ionosphere}

The COST 296 activities of space weather impact were mainly directed onto mid-latitudes, but some investigations in high latitudes have also been carried out.

\subsection{Manifestation of strong geomagnetic storms in the ionosphere above Europe}

Large-scale numerical simulations show that there is an increasing understanding of the geomagnetic storm scenarios/mechanisms and influences of storm onset time, intensity and season on the consequent changes in the ionosphere (e.g. Araujo-Pradere et al., 2004; Prölss, 2004). Nevertheless, some features of this phenomenon are still not clear and hardly predictable. Continuing investigations of the effects of strong geomagnetic storms on the ionosphere over Europe show that the problems are still unsolved as, e.g. the occasional enhance- ments of $F 2$ region peak electron density before the beginning of geomagnetic storms or the forecasting of an appearance of positive and negative phases within stormy periods over middle latitudes.

According to long-term ionospheric observations above European middle latitudes, storm-induced variations of the $F 2$ region ionisation during the storm main phase often change from large enhancements (positive phase) to depletions (negative phase). Such a change in signs of the storm effect makes a systemic description and prediction of the disturbed ionosphere rather complicated. Moreover, the distribution of storm effects may vary substantially from one event to another. A statistical picture of the occurrence of negative and positive phases during 65 strong-to-severe geomagnetic storms main phase for the period from 1995 to 2005 for three European stations is given in fig. 12 (Burešová et al., 2007).

The analysis shows that the changeover from one type of the effects to the other is more

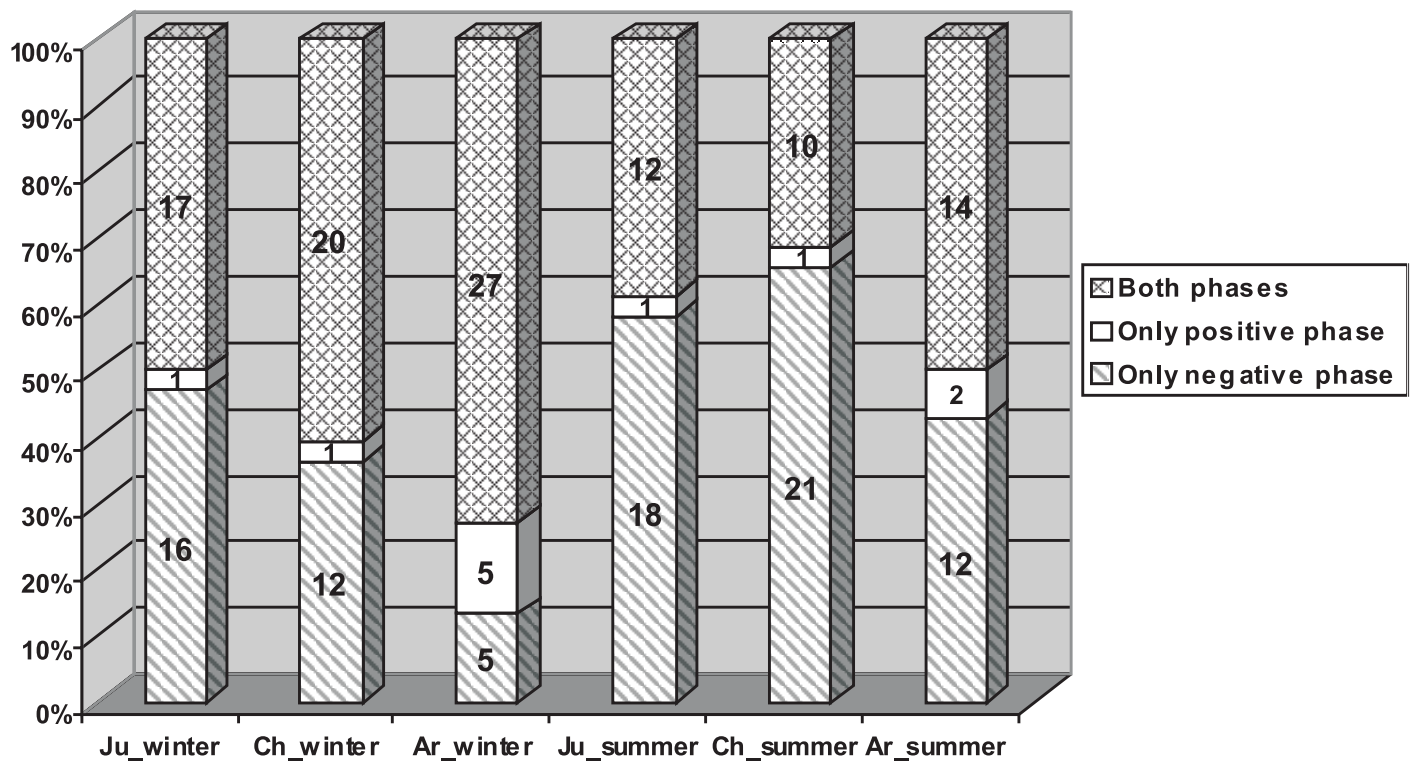

Fig. 12. Occurrence of negative and positive ionospheric phases during geomagnetic storm main phase above three European stations Juliusruh, Chilton and El Arenosillo for winter and summer half year during the period 1995-2005 (Burešová et al., 2007). 
common for winter than for summer, and the occurrence of such behaviour increases with decreasing latitude.

During summer half year all three stations display more frequent appearance of only negative effect during entire main phase of the analysed storms.

Considering both winter and summer periods the higher-middle latitude station Juliusruh shows much higher appearance of only negative phases ( 34 events) or both phases (29 events) than the appearance of only positive phase ( 2 events).

Summer-winter difference in storm phase appearance above Juliusruh is relatively small. Higher-middle latitude station Chilton shows a similar distribution of storm phases and more frequent appearance of negative phases in summer compared with Juliusruh.

Lower-middle latitude station El Arenosillo exhibits a shift to more frequent appearance of the positive phase, especially during wintertime.

Among storms with only positive phase, wintertime storms dominate.

\subsection{Pre-storm electron density enhancements at middle latitudes}

An enhancement of electron density in the maximum of the $F 2$ region $(\mathrm{NmF} 2)$ is sometimes observed several hours up to a day before the onset of a geomagnetic storm. Socalled pre-storm enhancements have been studied much less than the storm-time behaviour of the $F 2$ region.

Kane (2005) and Blagoveschensky et al. (2006) observed a strong pre-storm enhancement for the geomagnetic super-storm of October 2003 and related substorms and discussed the possibility to use this phenomenon as storm precursor.

Chukwama (2007) analysed effects of three very strong storms at 19 worldwide distributed stations and found no pre-storm effect for one event and pre-storm effects at 16 stations for the two other events.

Burešová and Laštovička (2007) analyzed 65 strong-to-severe geomagnetic storms in the
European area in the period 1995-2005 with the following results:

1) Strong pre-storm enhancements $(\delta N m F 2$ $>44 \%$, i.e. $\delta f o F 2>20 \%$ ) occur relatively often, in $20-25 \%$ of events. IRI and other models do not capture them. Solar flares may occasionally strengthen them, but they are not the main driver of the pre-storm enhancements.

2) Pre-storm enhancements of $N m F 2$ occur both during day and night. They seem to display a seasonal variation with higher occurrence frequency in the summer half year and a tendency to a solar cycle variation with apparent absence of pre-storm enhancements in the solar cycle maximum period. They do not reveal a systematic latitudinal variation. A systematic change of $h m F 2$ during the pre-storm enhancements was not observed.

3) The dominant mechanism remains to be uncovered but some potential mechanisms were excluded as the main drivers of the pre-storm enhancements: solar flares (they can only occasionally strengthen the pre-storm enhancements), soft particle precipitation in dayside cusp, magnetospheric electric field penetration, and auroral region activity expressed via the $\mathrm{AE}$ index.

Figure 13 shows an example of the pre-storm enhancement of $N m F 2$, observed more than half a day before the geomagnetic storm; this is the largest pre-storm enhancement within the period 1995-2005, partly amplified by a strong solar flare (Burešová and Laštovička, 2007).

To study the longitudinal extent, Burešová and Laštovička (2008) analyzed the behaviour of foF 2 for two US mid-latitudinal stations, Boulder and Millstone Hill, and two mid-latitudinal East Asian stations, Wakkanai and Beijing, during the pre-storm enhancement events observed in Europe.

Taking into account that the European, American and East Asian sectors are roughly separated by $120^{\circ}$ in longitude each other, it was concluded that the pre-storm enhancements are neither local/regional, nor global events. Their size is typically between about $120^{\circ}-240^{\circ}$ of longitude.

Burešová and Laštovička (2008) broadened the analysis of pre-storm events also downwards into the $E$ - and $F 1$-regions. There is no 

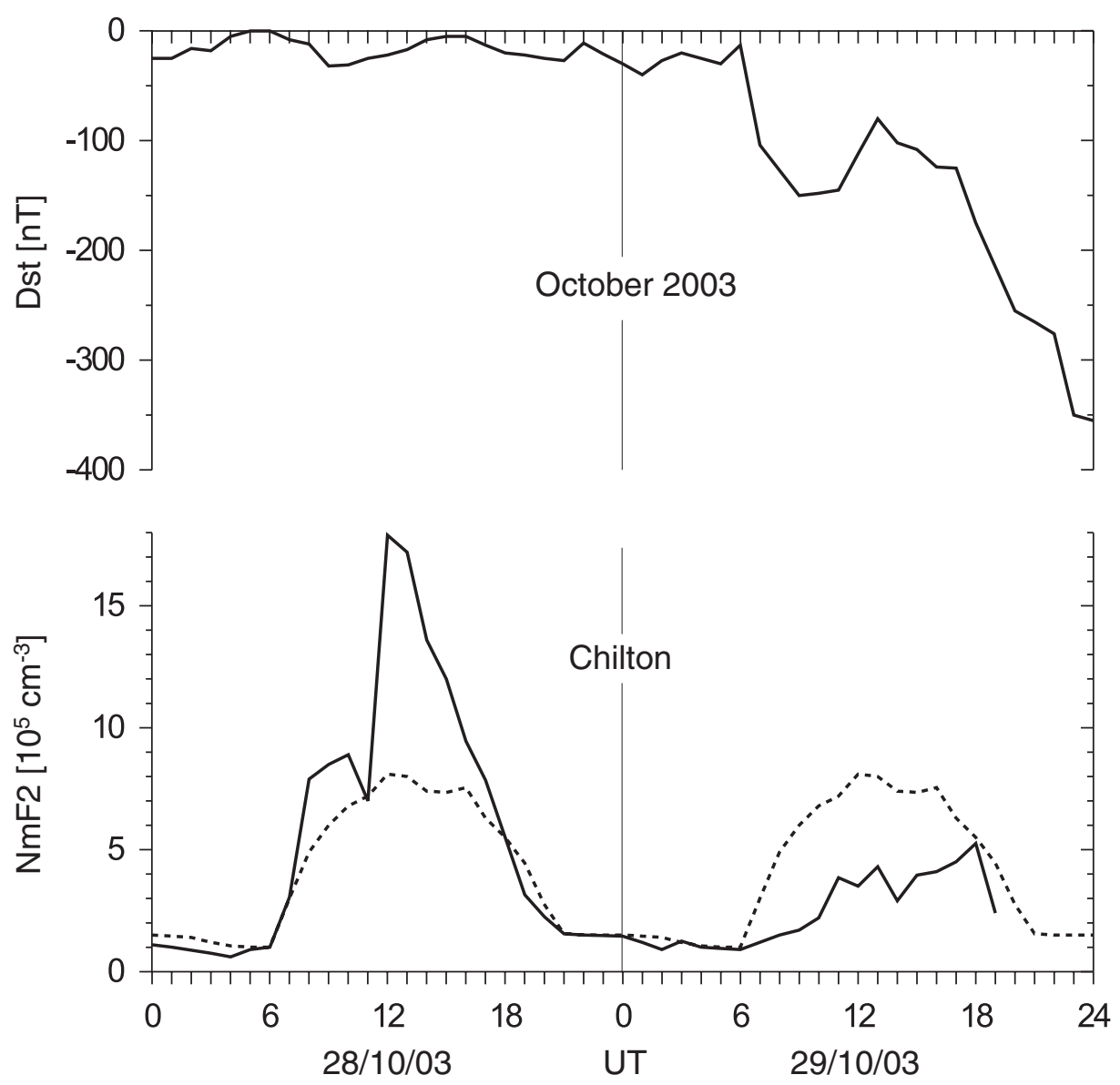

Fig. 13. Effects of the late October 2003 geomagnetic super-storm on $N m F 2$ for Chilton, England. Top plot: hourly $\mathrm{D}_{\mathrm{st}}$ variation, October 28-30. Bottom plot: $N m F 2$ (hourly values) response; full line - measured values, dashed line - monthly median values. A large pre-storm enhancement occurs in the middle of the day before the storm.

systematic pre-storm effect at the $F 1$ region heights.

Thus the mechanism responsible for prestorm events differs from that responsible for geomagnetic storms. Also in the $E$ layer no prestorm enhancements do occur contrary to the reported occurrence of the $f o E$ enhancements for the positive $Q$-disturbances (Mikhailov et al., 2007a).

This means that the origin of the pre-storm enhancements also differs from the origin of Mikhailov's positive $Q$-disturbances.

\subsection{Ionospheric response to solar proton events}

Dramatic ionization enhancements in the lower ionosphere are caused by solar proton events (SPEs), which are major, though infrequent, space weather phenomena. At polar regions, SPEs can cause radio blackouts lasting for days. The SPE, and particle precipitation in general, lead to production of odd hydrogen $\mathrm{HO}_{\mathrm{x}}\left(\mathrm{H}+\mathrm{OH}+\mathrm{HO}_{2}\right)$ through chemistry associated with ion pair production, water clus- 

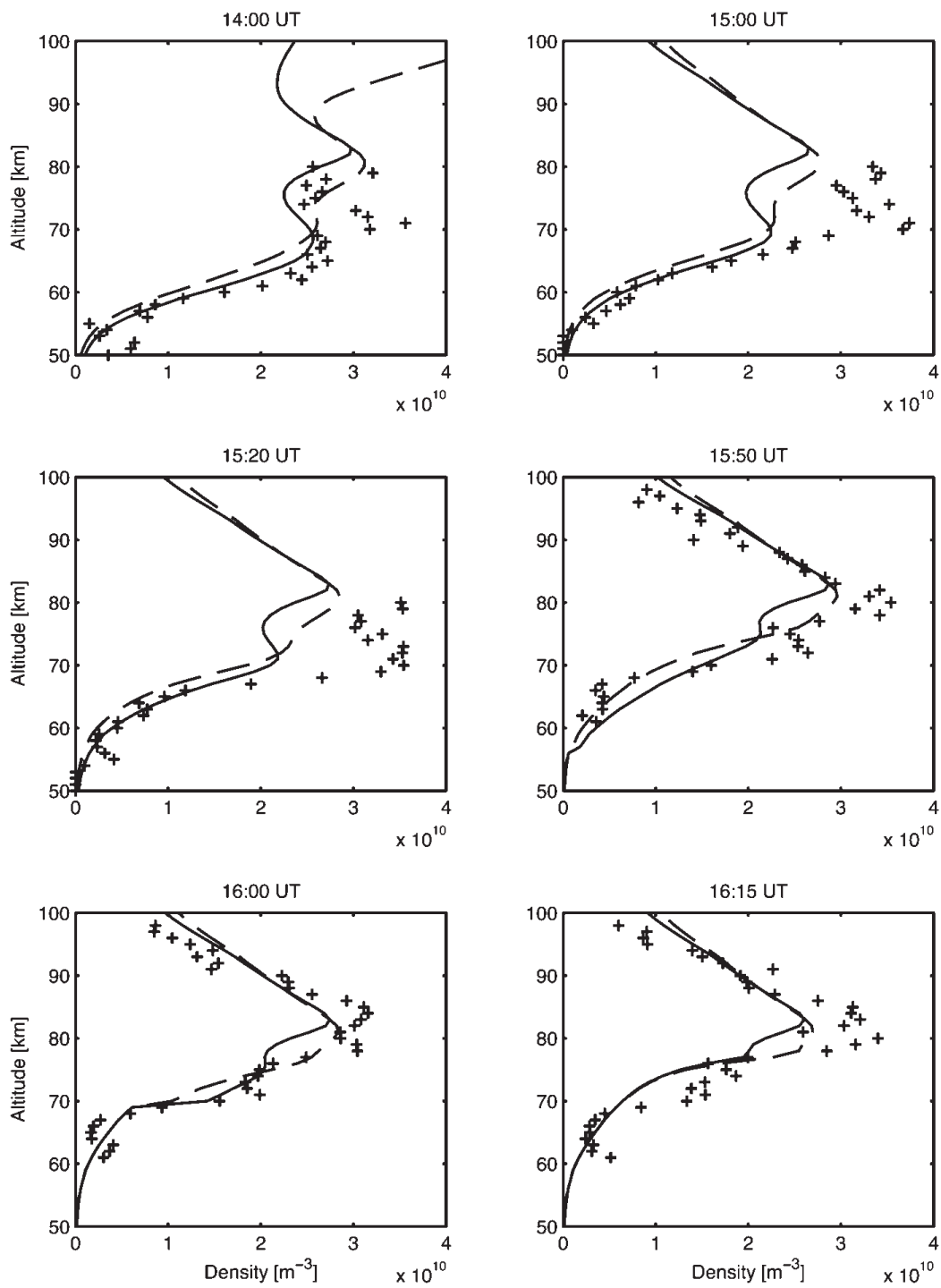

Fig. 14. The effect of the solar proton event on 23rd of October 1989 on $D$-region electron densities. Profiles are presented for selected times before, during, and after sunset. EISCAT incoherent scatter data are shown as crosses (+), and model electron densities using different (NO) profiles as solid and dashed lines (Verronen et al., 2006).

ter ion formation, and subsequent neutralization, and to production of odd nitrogen $N O_{x}$ $\left(\mathrm{N}+\mathrm{NO}+\mathrm{NO}_{2}\right)$ through dissociation of molecular nitrogen via charged particle impact and ion chemistry.
Coupling of the ionized and neutral atmosphere during high ionization events was studied during several selected solar proton events, using the coupled ion-neutral chemistry SIC (Sodankyla Ion Chemistry) model. A detailed 
overview of the model was given by Verronen et al. (2005). Understanding of the latitudinal effects of SPEs depends upon knowledge of the dynamic rigidity cutoffs imposed by the changing total magnetic field. A detailed study by Rodger et al. (2006) on dynamic geomagnetic rigidity cutoff variations was used to guide further modeling of the atmospheric impact of SPEs.

The model approach was validated and compared with experimental data from EISCAT incoherent scatter radar (one example is shown in fig. 14), VLF radio propagation experiments and different satellite observations (Clilverd $e t$ al., 2006; Verronen et al., 2007). Some natural variations are now quantitatively understood. According to modeling results on sunset transition of negative charge (Verronen et al., 2006), sunset decreases in the amount of atomic oxygen and $O_{2}\left({ }^{1} \Delta g\right)$ are such that they can be used to explain the observed spectral width changes of incoherent scatter radar measurements. Studies on high energy electron precipitation from different mechanisms (Rodger et al., 2007; Turunen et al., 2009) show the importance of time scales of the forcing of the atmosphere. Short lasting events, such as relativistic microbursts, seem to have little effect on the atmosphere.

The ionospheric and geomagnetic response of the strong solar events in September 2005 have been studied using simultaneous observations of the ionospheric absorption with a 30 $\mathrm{MHz}$ riometer at the Mario Zucchelli Station (Antarctica) and of geomagnetic activity recorded at Scott Base, and solar energetic proton fluxes in different energy ranges (GOES 11); their connections have been analyzed in detail by Perrone et al. (2009).

\section{Summary and conclusions}

The presented results give new information for a better understanding of the climate of the upper atmosphere and should help for ionospheric prediction purposes and for mitigation of ionospheric effects on radio systems.

Due to a close international cooperation there are many new results concerning investigation of long-term trends in the upper atmos- phere and here mainly in the ionosphere (Section 2). Concerning the practical aspect of ionospheric radio propagation there is general agreement that the trends in the ionosphere until now are small and can be neglected for most applications. Concerning the physical explanation of these trends there are two possibilities, the influence of increasing greenhouse gases and changes in the atmospheric ozone content or the influence of long-lasting changes of the geomagnetic activity. For most parts of the Earth's atmosphere a first, but very satisfying scenario of global change in the upper atmosphere at heights above $50 \mathrm{~km}$ has been developed basing on the greenhouse effect (Laštovička et al., 2006a). Section 2 presented some additional results that support this scenario. But there are also arguments that the trends in the ionosphere may be caused by geomagnetic long-term variations (Mikhailov (2002, 2006, 2008). For example, thermospheric cooling can hardly be seen in $f o F 2$ trends due to a weak $N m F 2$ dependence on neutral temperature. Also recent model calculations (Qian et al., 2008) provide a very weak impact of the greenhouse cooling on foF 2 . For a final solution of this problem additional observations and model activities are necessary in the future. Also the investigations of trends in the MLT wind fields have to be continued.

Wave phenomena in the atmosphere (Section 3) are very important for understanding of the variability of the ionosphere. Very important are the results of the burst-like occurrence of planetary waves (Laštovička et al., 2006c) of different periods, which can probably be helpful in future for a better medium-scale prediction. The results presented for gravity waves and infrasonic waves are important for the explanation of smaller-scale disturbances.

Section 4 presented new results concerning ionospheric variability presented which are essential for practical aspects of ionospheric prediction activities. Here the analyses of different ionospheric parameters in dependence on local time, season, latitude, and altitude will be very helpful. With the detection and analysis of the so-called $Q$-disturbances (Mikhailov et al., 2004) a new phenomenon was introduced which can essentially contribute to the under- 
standing of the ionospheric variability during quiet geomagnetic activity conditions. The use of incoherent scatter radars is very valuable for the explanation of the $Q$-disturbances.

Some results concerning space weather impact on the ionosphere were described in Section 5. Whereas the statistical investigations of ionospheric storms and of pre-storm events are carried out for the European region, the ionospheric reactions due to very strong solar events have been investigated by use of ionospheric absorption measurements in Antarctica. Similar effects can of course also be detected at northern polar latitudes. The impact of precipitating high energetic particles on the Earth's ionosphere and atmosphere can successfully be investigated only with a complex model (e.g. with the Sodankyla Ion Chemistry model). Also incoherent scatter data are very helpful for this purpose.

In conclusion it can be stated that during the last 4 years in the frame of the COST 296 project many new and very important results have been derived due to a close cooperation between different European teams. These results improve our knowledge about the climate of the upper atmosphere but also create new questions for future investigations.

\section{Acknowledgements}

Authors are grateful to project COST 296 for support. J.L. and D.B. acknowledge support by grant OC091 of the Ministry of Education, Youth and Sports of the Czech Republic.

The contribution of David Altadill has been partly supported by project CGL2006-12437C02-02/ANT of the Ministry of Education and Science of Spain.

\section{REFERENCES}

Akmaev, R.A., V.I. Fomichev and X. ZhU (2006): Impact of middle-atmospheric composition changes on greenhouse cooling in the upper atmosphere, J. Atmos. Solar-Terr. Phys., 68, 1879-1889, doi:10.1016/j.jastp.2006.03.008.

Alfonsi, L., G. De Franceschi and L. Perrone (2002): Long-term trends of the critical frequency of the $F 2$ layer at northern and southern high latitude regions, Phys. Chem. Earth, 27 (6-8), 595-600.
Alfonsi, L., G. De Franceschi and A. De Santis (2008): Geomagnetic and ionospheric data analysis over Antarctica: a contribution to the long-term trends investigation, Ann. Geophysicae, 26, 1173-1179.

Altadill, D. (2007): Time/altitude electron density variability above Ebro, Spain, Adv. Space Res., 39 (5), 962969, doi:10.1016/j.asr.2006.05.031.

Altadill, D. and E.M. Apostolov (2003): Time and scale size of planetary wave signatures in the ionospheric $F$ region. Role of the geomagnetic activity and mesosphere/lower thermosphere winds, J. Geophys. Res., 108 (A11), 1403, doi:10.129/2003JA010015.

Altadill, D., D. Arrazola, E. Blanch and D. Buresova (2008): Solar activity variations of ionosonde measurements and modeling results, Adv. Space Res., 42 (4), 610-616, doi:10.1016/j.asr.2007.07.028.

Araujo-Pradere, E.A. and T.J. Fuller-Rowell (2004): Time Empirical Ionospheric Correction Model (STORM) response in IRI 2000 and challenges for empirical modelling in the future, Radio Sci., 39 (1), RS1S24, doi:10.1029/2002RS002805.

BARKER, D.N., C.A. BARTH, K.E. MANKOFF, S.G. KANEKAL, S.M. BAILY, G.M. MASON and J.E. MAZur (2001): Relationship between precipitating auroral zone electrons and lower thermospheric nitric oxide densities: 19982000, J. Geophys. Res., 106, 24465-24480, 2001.

Bencze, P. (2005): On the long-term change of ionospheric parameters, J. Atmos. Solar-Terr. Phys., 67, 1298-1306.

Bencze, P. (2007): What do we know of the long-term change of the Earth's ionosphere?, Adv. Space Res., 40, 1121-1125.

Blagoveschensky, D.V., J.W. MacDougall and A.V. PIATKOVA (2006): Ionospheric effects preceding the October 2003 Halloween storm, J. Atmos. Solar-Terr. Phys., 68, 821-831.

Borries, C., N. JAKOWSKI, Ch. JACOBI, P. HoFFMANN and A. Pogoreltsev (2007): Spectral analysis of planetary waves seen in ionospheric total electron content (TEC): First results using GPS differential TEC and stratospheric reanalyses, J. Atmos. Solar-Terr. Phys., 69, 2442-2451.

BREMER, J. (2008): Long-term trends in the ionospheric $E$ and $F 1$ regions, Ann. Geophysicae, 26, 1189-1197.

BREMER, J. and U. BERGER (2002): Mesospheric temperature trends derived from ground-based LF phase-height observations at mid-latitudes: comparison with model simulations, J. Atmos. Solar-Terr. Phys., 64, 805-816.

Bremer, J. and D. Peters (2008): Influence of stratospheric ozone changes on long-term trends in the meso- and lower thermosphere, J. Atmos. Solar-Terr. Phys., 70, 1473-1481, doi:10.1016/j.jastp.2008.03.024.

BureŠovÁ, D. and J. LAŠTOVIČKA (2007): Pre-storm enhancements of $f o F 2$ above Europe, Adv. Space Res., 39, 1298-1303.

BuREŠOvÁ, D. and J. LAŠTOVIČKa (2008): Pre-storm electron density enhancements at middle latitudes, J. Atmos. SolarTerr. Phys, 70, 1848-1855, doi:10.1016/j.jastp.2008.01.014.

BureŠová, D., J. LaštovičKa, and G. DE FRANCESCHI (2007): Manifestation of strong geomagnetic storms in the ionosphere above Europe, in Space Weather Research towards Applications in Europe, edited by J. LiLENSTEN, (Springer, Dordrecht), pp. 185-202.

Chukwama, V.U. (2007): On positive and negative ionospher- 
ic storms, Acta Geodet. Geophys. Hungarica, 42, 1-21.

Chum, J., J. LaštovičKa, T. Sindelářová, D. Burešová and F. HRUŠKA (2008a): Peculiar transient phenomena observed in the infrasound range, J. Atmos. Solar-Terr. Phys., 70, 866-878.

Chum, J., F. HruŠKa, D.Burešová, T. Šindelářová, P. HeJDA and J. BocHNíČEK (2009): Multipoint continuous Doppler sounding in the Czech Republic and geomagnetic Pi2 pulsations; first results, Adv. Space Res., 44, doi:10.1016/j.jasr.2009.04.030.

Clilverd, M.A., T.D.G. Clark, E. Clarke and H. Rishbeth (1998): Increased magnetic storm activity from 1868 to 1995, J. Atmos. Solar-Terr. Phys., 60, 1047-1056.

Clilverd, M.A., A. Seppälä, C.J. Rodger, N.R. ThOMson, P.T. Verronen, E. Turunen, Th. Ulich, J. LichtenBERGER and P. Steinbach (2006): Modelling polar ionospheric effects during the October-November 2003 solar proton events, Radio Science, 41, RS2001, doi:10.1029/2005RS003290.

Danilov, A.D. and A.V. Mikhailov (1999): Spatial and seasonal variations of the $f o F 2$ long-term trends, Ann. Geophysicae, 17, 1239-1243.

De Franceschi, G., T.L. Gulyaeva, L. Perrone and B. ZOLESI (1999): MAC: An Oriented Magnetic Activity Catalogue for Ionospheric Applications, U.R.S.I. International Reference Ionosphere News Letter, 6 (4), 5-6.

Depueva, A.H., A.V. Mikhailov and V.H. Depuev (2005): Quiet time F2-layer disturbances at geomagnetic equator, Int. J. Geomag. Aeronom, 5, 1-11, GI3001, doi:10.1029/2004GI000071.

De SANTiS, A. (2007): How persistent is the present trend of the geomagnetic field to decay and, possibly, to reverse?, Phys. Earth Planet. Interiors, 162, 217-226.

EMmerT, J.T., J.M. Picone, J.L. LEAN and S.H. KNOWLES (2004): Global change in the thermosphere: Compelling evidence of a secular decrease in density, J. Geophys. Res., 109, A02301, doi:10.1029/2003JA010176.

Fotiadis, D.N. and S.S. KouRIS (2006a): A functional dependence of $f o F 2$ variability on latitude, Adv. Space Res., 37, 1023-1028.

FotiADIS, D.N. and S.S. KouRIS (2006b): Capturing the morphology of long-duration negative ionospheric disturbances using an empirical pattern recognition method, Radio Science, 41, RS6012,doi:10.1029/2005RS003395.

Fotiadis, D.N., S.S. Kouris, V. Romano and B. ZolesI (2004): Climatology of ionospheric F-region disturbances, Ann. Geophysics, 47, 1311-1323.

Gavrilov, N.M., S. FukaO, T. Nakamura, Ch. Jacobi, D. KÜRSCHNER, A.H. MANSON and C.E. MEeK (2002): Comparative study of interannual changes of the mean winds and gravity wave activity in the middle atmosphere over Japan, Central Europe and Canada, J. Atmos. Solar-Terr. Phys., 64, 1003-1010.

GEORGES, T. (1973): Infrasound from convective storms: Examining the evidence, Rev. Geophys., 11 (3), 571-594.

Gordienko, G.I., I.N. Fedulina, D. Altadill and M.G. SHEPHERD (2007): Upper ionosphere variability over Alma-Ata and Observatorio del Ebro using the $\triangle f o F 2$ data obtained during the winter/spring period of 2003/2005, J. Atmos. Solar-Terr. Phys., 69, 2452-2464.

Ivanov-KHOLODNY, G.S. and A.A. NusinOv (1979): The formation and dynamics of the daytime mid-latitude ionospheric E-layer, Trudi IAG, 37, pp. 128 (in Russian).
JACOBI, CH. and D. KÜRSCHNER (2006): Long-term trends of MLT region winds over Central Europe, Phys. Chem. Earth, 31, 16-21.

JACOBI, CH., N.M. GavriLOv, D. KÜRSChNER and K. FRÖHLICH (2006): Gravity wave climatology and trends in the mesosphere/lower thermosphere region deduced from low-frequency drift measurements 1984-2003 $\left(52.1^{\circ} \mathrm{N}, 13.2^{\circ} \mathrm{E}\right)$, J. Atmos. Solar-Terr. Phys., 68, 1913-1923.

Jacobi, Ch., K. Fröhlich, C. Viehweg, G. Stober and D. KÜRSCHNER (2007): Midlatitude mesosphere/lower thermosphere meridional winds and temperatures measured with meteor radar, Adv. Space Res., 39, 1278-1283.

JACOBI, CH., G. Stober and D. KÜRSChNer (2008): Connection between winter mesopause region temperatures and diurnal LF reflection height variations measured at Collm, Adv. Space Res., 41, 1482-1433.

Jakowski, N., S.M. Stankov, V. Wilken, C. Borries, D. Altadill, J. Chum, D. Burešová, J. Boska, P. Sauli, F. HRUSKA and L. CANDER (2008): Ionospheric behaviour over Europe during the solar eclipse of 3 October 2005, J. Atmos. Solar-Terr. Phys., 70, 836-853.

JARVIS, M.J. (2005): Observed tidal variation in the lower thermosphere through the 20th Century and the possible implication of ozone depletion, J. Geophys. Res., 110 (A4), A04303, doi:10.1029/2004JA010921.

KANE, R.P. (2005): Ionospheric foF 2 anomalies during some intense geomagnetic storms, Ann. Geophysicae, 23, 2487-2499.

KouRIS, S.S. (2008): Thresholds of TEC variability describing the plasmaspheric disturbed state, Acta Geophysica, 56, 408-416.

KouRIS S.S., D.N. Fotiadis and T.D. Xenos (1998): On the day-to-day variation of $f o F 2$ and $\mathrm{M}(3000) \mathrm{F} 2, A d v$. Space Res., 22 (6), 872-876.

Kouris S.S., LJ. R. CANDER and K.V. POLIMERIS (2005): On the variability of SLAB Thickness, ESA/ESTEC, 2nd European Space Weather Week, 14-18 November 2005, Noordwjk, The Netherlands, ESA-ESWW2.

Kouris, S.S., K.V. Polimeris and Lj. R. CANDER (2006a): Specifications of TEC variability, Adv. Space Res., 37, 983-1004.

Kouris S.S., K.V. Polimeris, V. Romano, B. Zolesi and L.R. CANDER (2006b): Within-the-hour variability: levels and their probabilities, Ann. Geophysics, 49 (4/5), 945-959.

Kouris, S.S., K.V. Polimeris, Lu. R. CANDer and L. CiraOLO (2008): Solar and latitude dependence of TEC and SLAB thickness, J. Atmos. Solar-Terr. Phys., 70, 13511365, doi:10.1016/j.jastp.2008.03.009.

Krasnov, V.M., Ya.V. DrobzheVa and J. LaštovičKa (2006): Recent advances and difficulties of infrasonic wave investigation in the ionosphere, Surv. Geophys., 27, 169-209.

Krasnov, V.M., Ya.V. Drobzheva and J. LaštovičKa (2007): Acoustic energy transfer to the upper atmosphere from sinusoidal sources and a role of non-linear processes, J. Atmos. Solar-Terr. Phys., 69, 1357-1365.

LAŠTOVIČKA, J. (2005): On the role of solar and geomagnetic activity in long-term trends in the atmosphere-ionosphere system, J. Atmos. Solar-Terr. Phys., 67 (1-2), 83-92. 
LAŠTOVIČKA, J. (2006): Forcing of the ionosphere by waves from below, J. Atmos. Solar-Terr. Phys., 68, 479-497.

LaštovičKa, J., R.A. AKMaEv, G. BeIg, J. BREMER and J.T. EMMERT (2006a): Global change in the upper atmosphere, Science, 314 (5803), 1253-1254.

LaštovičKa, J., A. V. Mikhailov, Th. Ulich , J. Bremer, A. G. Elias, N. Ortiz de Adler, V. Jara, R. Abarca DEl Rio, A. J. Foppiano, E. Ovalle and A.D. Danilov (2006b): Long-term trends in $f o F 2$ : A comparison of various methods, J. Atmos. Solar-Terr. Phys., 68 (17), 1854-1870.

LAŠTOVIČKa, J., P. ŠAULI and P. KRIŽAN (2006c): Persistence of the planetary wave type oscillations in the midlatitude ionosphere, Annals Geophys., 49 (6), 1189-1200.

LaštovičKa, J., R.A. Akmaev, G. Beig, J. Bremer, J.T. EMmert, C. Jacobi, M.J. Jarvis, G. Nedoluha, Yu.I. PORTNYAGIN and T. ULICH (2008a): Emerging pattern of global change in the upper atmosphere and ionosphere, Ann. Geophysicae, 26, 1255-1268.

LAŠTOVIČKA, J., X. YUE and W. WAN (2008b): Long-term trends in foF 2: their estimating and origin, Ann. Geophysicae, 26, 593-598.

Marin, D., A.V. Mikhailov, B.A. DE la Morena and M. HERRAIZ (2001): Long-term $h m F 2$ trends in the Eurasian longitudinal sector on the ground-based ionosonde observations, Ann. Geophysicae, 19, 761-772.

Mikhailov, A.V. (2002): The geomagnetic control concept of the F2-layer parameter long-term trends, Phys. Chem. Earth, 27, 595-606.

Mikhailov, A.V. (2006): Trends in the ionospheric E-region, Phys. Chem. Earth, 31, 22-23.

MikHailov, A.V. (2008): Ionospheric F1 layer long-term trends and the geomagnetic control concept, Ann. Geophysicae, 26, 3793-3803.

MikHAiLOV, A.V. and D. MARIN (2000): Geomagnetic control of the foF 2 long-term trends, Ann. Geophysicae, 18, 653-665.

Mikhailov, A.V. and B.A. DE LA Morena (2003): Longterm trends of $f o E$ and geomagnetic activity variations, Ann. Geophysicae, 21, 751-760.

Mikhailov, A.V. and K. SchlEgel (2003): Geomagnetic storm effects at $F 1$-layer heights from incoherent scatter observations, Ann. Geophysicae, 21, 583-596.

Mikhailov, A.V., A.H. Depueva and T. Yu. LeschinsKaya (2004): Morphology of quiet time F2-layer disturbances: High and lower latitudes, Int. J. Geomag. Aeronom, 5, 114, GI1006, doi:10.1029/2003GI000058.

Mikhailov, A.V., V.H. Depuev and A. H. Depueva (2007a): Synchronous $N m F 2$ and $N m E$ daytime variations as a key to the mechanism of quiet-time $F 2$-layer disturbances, Ann. Geophysicae, 25, 483-493.

Mikhailov, A.V., A.H. Depueva and V.H. Depuev (2007b): Daytime F2-layer negative storm effect: what is the difference between storm-induced and $Q$-disturbance events?, Ann. Geophysicae, 25, 1531-1541.

Mursula, K. and D. Martini (2006): Centennial increase in geomagnetic activity: Latitudinal difference and global estimates, J. Geophys. Res., 111, A08209, doi:10.1029/2005JA011549.

Perrone, L., M. Parisi, A. Meloni , M. Damasso and M. GALLIANI (2009): Study on solar sources and polar cap absorption events recorded in Antarctica, Adv. Space Res., 43 (11), 1660-1668.
PRÖLSS, G.W. (1995): Ionospheric $F$-region storms, in Handbook of Atmospheric Electrodynamics, vol. 2, edited by H. Volland, H., (CRC Press/Boca Raton), pp. 195-248.

PRöLsS, G.W. (2004): Physics of the Earth's space environment, (Springer-Verlag Berlin Heidelberg, Germany).

Qian, L., S.C. Solomon, R.G. Roble and T.J. Kane (2008): Secular change in the coupled thermosphere and ionosphere system, Geophys. Res. Lett., 35, L07811, doi:10.1029/2007GL033156.

Ridley, A.J., G. Crowley, R. LinK, R. Frahm, J.D. WiNNINGHAM and J.R. SHARbER (1999): Variations of the thermospheric nitric oxide mass mixing ratio as a function of Kp, altitude, and magnetic local time, Geophys. Res. Lett., 26, 1541-1544.

Rishbeth, H. (1990): A greenhouse effect in the ionosphere?, Planet. Space Sci., 38, 945-948.

Rishbeth, H. and R.G. Roble (1992): Cooling of the upper atmosphere by enhanced greenhouse gases-modelling of thermospheric and ionospheric effects, Planet. Space Sci., 40, 1011-1026.

RoBLE, R.G. and R.E. DiCKINSON (1989): How will changes in carbon dioxide and methane modify the mean structure of the mesosphere and lower thermosphere?, Geophys. Res. Lett., 16, 1441-1444.

Rodger, C.J., M.A. Clilverd, P.T. Verronen, Th.Ulich, M.J. JARVIS and E. TURUNEN (2006): Dynamic geomagnetic rigidity cutoff variations during a solar proton event, $J$. Geophys. Res., 111, A04222, doi:10.1029/2005JA011395.

Rodger, C.J., M.A. Clilverd, D. NunN, P.T. VerRonen, J. BorTniK and E. TuRUnen (2007): Stormtime, shortlived bursts of relativistic electron precipitation detected by subionospheric radio wave propagation, J. Geophys. Res., 112, A07301, doi: 10.1029/2007JA012347.

ŠAUli, P., P. ABRY, D. Altadill and J. BoŠKa (2006a): Detection of the wave-like structures in the F-region electron density: Two station measurements, Studia Geoph. Geod., 50 (1), 131-146, doi:10.1007/s11200006-0007-y.

ŠAuli, P., P. Abry, J. BošKa and L. Duchayne (2006b): Wavelet characterisation of ionospheric acoustic and gravity waves occurring during the solar eclipse of August 11, 1999, J. Atmos. Solar-Terr. Phys., 68, 586-598.

ŠAuli, P., S.G. Roux, O. ABry and J. BoŠKa (2007): Acoustic-gravity waves during solar eclipse: Detection and characterization using wavelet transforms, J. Atmos. Solar-Terr. Phys., 69, 2465-2484.

Šindeláǩ́ová, T., D. Burešová, J. Chum and F. HrušKa (2009): Doppler observations of infrasonic waves of meteorological origin at ionospheric heights, Adv. Space Res., 43 (11), 1644-1651, doi:10.1016/j.asr.2008.08.022.

Turunen, E., P.T. Verronen, A. SeppäLä, C.J. Rodger, M.A. Clilverd, J. Tamminen, C.-F. Enell and Th. ULICH (2009): Impact of different particle precipitation energies on $\mathrm{NO}_{\mathrm{x}}$ generation during geomagnetic storms, J. Atmos. Solar-Terr. Phys., 71, 1176-1189. doi:10.1016/j.jastp.2008.07.005.

Verronen, P.T., A. SePpÄlä, M.A. Clilverd, C.J. Rodger, E. Kyrölä, C.-F. Enell, Th.Ulich and E. Turunen (2005): Diurnal variation of ozone depletion during the October-November 2003 solar proton events, J. Geophys. Res., 110, A09S32, doi: 10.1029/2004JA010932. 
Verronen, P.T., Th. Ulich, E. Turunen and C.J. Rodger (2006): Sunset transition of negative charge in the $D$ region ionosphere during high-ionization conditions, Ann. Geophysicae, 24, 187-202.

Verronen, P.T., C.J. Rodger, M.A. Clilverd, H.M. Pick-
ETT and E. TURUNEN (2007): Latitudinal extent of the January 2005 solar proton event in the Northern Hemisphere from satellite observations of hydroxyl, Ann. Geophysicae, 25, 2203-2215, SRef-ID: 1432-0576/angeo/2007-25-2203. 